NBER WORKING PAPER SERIES

CAN INVESTORS TIME THEIR EXPOSURE TO PRIVATE EQUITY?

\author{
Gregory Brown \\ Robert S. Harris \\ Wendy $\mathrm{Hu}$ \\ Tim Jenkinson \\ Steven N. Kaplan \\ David T. Robinson \\ Working Paper 26755 \\ http://www.nber.org/papers/w26755
}

\author{
NATIONAL BUREAU OF ECONOMIC RESEARCH \\ 1050 Massachusetts Avenue \\ Cambridge, MA 02138 \\ February 2020
}

The authors are grateful to Manuel Adelino, Oleg Gredil, Per Stromberg, Michael Cembalest and seminar participants at the 2017 Private Equity Research Consortium Symposium, the 2019 Southern California Private Equity Conference, and the AlpInvest London LP Roundtable for their helpful feedback and suggestions. We thank the Private Equity Research Consortium and the UAI Foundation for their support and Burgiss for supplying data. The views expressed herein are those of the authors and do not necessarily reflect the views of the National Bureau of Economic Research.

At least one co-author has disclosed a financial relationship of potential relevance for this research. Further information is available online at http://www.nber.org/papers/w26755.ack

NBER working papers are circulated for discussion and comment purposes. They have not been peer-reviewed or been subject to the review by the NBER Board of Directors that accompanies official NBER publications.

(C) 2020 by Gregory Brown, Robert S. Harris, Wendy Hu, Tim Jenkinson, Steven N. Kaplan, and David T. Robinson. All rights reserved. Short sections of text, not to exceed two paragraphs, may be quoted without explicit permission provided that full credit, including $(\odot)$ notice, is given to the source. 
Can Investors Time Their Exposure to Private Equity?

Gregory Brown, Robert S. Harris, Wendy Hu, Tim Jenkinson, Steven N. Kaplan, and David T. Robinson

NBER Working Paper No. 26755

February 2020

JEL No. G23,G24

\section{ABSTRACT}

Private equity performance, both for buyouts and venture capital, has been highly cyclical: periods of high fundraising have been followed by periods of low performance. Despite this seemingly predictable variation, we find modest gains, at best, to pursuing realistic, investable strategies that time capital commitments to private equity. This occurs, in part, because investors can only time their commitments to funds; they cannot time when commitments are called or when investments are exited. There is a high degree of time-series correlation in net cash flows even across commitment strategies that allocate capital in a very different manner over time.

\author{
Gregory Brown \\ University of North Carolina at Chapel Hill \\ Kenan-Flagler Business School \\ gregwbrown@unc.edu \\ Robert S. Harris \\ University of Virginia \\ Darden School of Business \\ 100 Darden Boulevard \\ Charlottesville, VA 22903 \\ HarrisR@darden.virginia.edu \\ Wendy $\mathrm{Hu}$ \\ Burgiss \\ 111 River Street, 10th Floor \\ Hoboken, NJ 07030 \\ WHu@burgiss.com
}

\author{
Tim Jenkinson \\ University of Oxford \\ Said Business School \\ Park End Street \\ Oxford OX1 1HP \\ United Kingdom \\ tim.jenkinson@sbs.ox.ac.uk \\ Steven N. Kaplan \\ Booth School of Business \\ The University of Chicago \\ 5807 South Woodlawn Avenue \\ Chicago, IL 60637 \\ and NBER \\ steven.kaplan@chicagobooth.edu \\ David T. Robinson \\ Fuqua School of Business \\ Duke University \\ 100 Fuqua Drive \\ Durham, NC 27708 \\ and NBER \\ davidr@duke.edu
}




\title{
Can Investors Time Their Exposure to Private Equity?
}

\begin{abstract}
Private equity performance, both for buyouts and venture capital, has been highly cyclical: periods of high fundraising have been followed by periods of low performance. Despite this seemingly predictable variation, we find modest gains, at best, to pursuing realistic, investable strategies that time capital commitments to private equity. This occurs, in part, because investors can only time their commitments to funds; they cannot time when commitments are called or when investments are exited. There is a high degree of time-series correlation in net cash flows even across commitment strategies that allocate capital in a very different manner over time.
\end{abstract}

\section{Introduction}

This paper uses data on over 3500 private equity funds (both buyout and venture capital) to investigate a distinguishing feature of many alternative assets which use closed-end fund structures. In these structures, limited partner investors can only time their capital commitments to funds; they cannot time when their commitments are called or when their investments are exited; these decision rights over cash flows are vested with the general partner. While there is considerable research on returns to private equity investing (e.g., see Kaplan and Sensoy (2015) for a survey) and a long literature on timing in public equity markets (e.g., see Ferson and Mo (2016)), this study is the first to investigate investor timing in private equity using comprehensive data spanning three decades.

Our first set of results are immensely practical for investors. We find the gains from implementable timing strategies (pro-cyclical and counter-cyclical) are modest at best and likely lead to organizational difficulties for large asset managers investing in private equity. This is despite well-documented cyclicality in private equity performance that associates high levels of 
fund raising with lower subsequent fund performance. ${ }^{1}$

The second set of results displays a key reason these timing benefits do not materialize and surfaces an uncertainty faced by investors in such funds. There is a high degree of time-series correlation in net cash distributions even across commitment strategies that allocate capital in a very different manner over time. In effect, the thread between performance and the timing of limited partner capital commitments is frayed by the commitment risk associated with delegating investment and exit activity to the general partner. The high correlations reflect general partners with funds in adjacent vintage years reacting to similar entry and exit conditions.

A feature of many 'alternative' assets is that investors must commit capital to funds, but decisions on when to invest the capital and eventually exit those investments are made solely by the fund manager. Such investment vehicles are typically structured as limited partnerships with the fund manager as general partner (GP) and capital being drawn down over the first few years of the fund life from limited partner (LP) investors. These partnerships are also usually selfliquidating within a defined time period. Examples of assets with such structures include private equity, infrastructure, private credit, natural resources, real estate, and funds-of-funds. This 'commitment' model of investing contrasts with conventional asset classes, such as listed equity and fixed income, in which capital is immediately invested once investors make an allocation decision.

In private equity, this commitment model provides the GP with the resources and flexibility to buy, manage and sell companies using its expertise, and in turn offers potentially higher returns to LP investors from tapping into GP talent. Since LP ownership interests are generally illiquid, returns typically come from waiting for GPs to exit and distribute cash, not from selling LP claims

\footnotetext{
${ }^{1}$ For evidence see Harris, Jenkinson and Kaplan (2014), Kaplan and Stromberg (2009) or Robinson and Sensoy (2016).
} 
on the fund. The distinction between commitment and cash flow creates challenges for investors seeking to allocate capital to alternative assets.

The temptation for investors to time commitments to private equity likely derives from the perception that private equity markets, both buyouts and venture capital (VC) are highly cyclical. ${ }^{2}$ The aggregate amount of capital committed to the sector varies substantially from peak to trough, and periods of high fundraising activity are followed by periods of low performance for the asset class. But can investors use realistic strategies to time their commitments to private equity to take advantage of this cyclicality in performance? For instance, if periods of high fundraising are known to be followed by low performance, then why not allocate capital in some appropriately counter-cyclical manner to avoid the well-documented episodes of low performance?

Using our data, we document the cyclical nature of performance in private equity over three decades. This is consistent with prior research, showing that periods of high fundraising are followed by lower performance. The effect is more pronounced in venture capital than in buyout; moreover, the effects on absolute performance are larger than on performance relative to public equity investing.

Despite these clear patterns, however, we show that there are only modest performance benefits from commitment strategies that investors might actually use to harness potential timing gains. These fall well short of the gains that might be hoped for from statistical patterns found in research; moreover, they must be weighed against organizational difficulties encountered in

\footnotetext{
${ }^{2}$ Other challenges include hitting a target asset allocation (which require larger commitments than the target, given that committed capital is, on average, not fully invested) and management of liquidity (to meet capital calls when they occur). Furthermore, if public markets fall dramatically (as in 2008), LPs can find themselves with capital commitments that are higher than the desired allocations to private equity. Managing cash flows requires effort in forecasting capital calls and distributions, a subject of considerable modeling in the industry (see for instance, Meads, Morandi and Carnelli (2016)). See Gredil (2015) for an analysis of the potential agency problems that fund managers face regarding the timing of exits.
} 
constantly shifting private equity allocations. We create a range of potential timing strategies with rules on how much to commit and whether this varies based on observable conditions in the private and public markets. This allows us to contrast contrarian (counter-cyclical) strategies, which reduce commitments in high fundraising periods, with pro-cyclical strategies and with neutral strategies which do not try to adjust for the fundraising cycle. Our timing strategies are based on measures of "hot" markets (high fundraising levels). For each strategy, we examine performance based on the full time-series of cash flows (cash calls and distributions) and net asset values that a limited partner investor would have experienced over our three decade sample period.

For buyouts, private equity investing beats public market returns, consistent with prior research, but the extra benefits of timing strategies are modest. A neutral strategy which does not time commitments pays back $\$ 1.80$ for every dollar invested (a multiple of 1.80 of absolute performance). Adjusted for the opportunity costs of not investing in the public markets, that multiple translates to a 1.15 public market equivalent (PME) of relative performance for the neutral strategy-that is 1.15 as much wealth as would have resulted from putting equivalently timed cash in public equity. ${ }^{3}$ By contrast, when we calibrate the fundraising cycle based on recent levels of fundraising scaled by the value of the stock market, a counter-cyclical (pro-cyclical) commitment strategy generates a multiple 1.86 (1.74) and a PME of 1.17 (1.09), quite comparable to the figures for the neutral strategy.

For venture capital, the more pronounced impact of the fundraising cycle on subsequent performance identified by our analysis and earlier research suggests even higher potential timing gains in VC than in buyout. Our results suggests these are hard, if not impossible, to harvest in

\footnotetext{
${ }^{3}$ See Kaplan and Schoar (2005) for a discussion of the public market equivalent performance metric.
} 
practice. The timing gains resulting from the implementable strategies are generally modest; moreover, timing measures to gauge the fundraising cycle send different signals on whether a counter-cyclical strategy is useful, complicating any attempt to adopt timing in practice. The patterns in VC reflect the difficulty in predicting market peaks ex ante; for example, 1997 and 1998 looked like fundraising peaks for venture capital from a historical standpoint, but were eclipsed by fundraising in 1999 and 2000, which made counter-cyclical strategies benchmarked against recent fundraising levels scale back too soon from an ex post perspective.

Since investors in private equity funds are typically large institutions, the potential timing benefits of adjusting annual allocations must be weighed against organizational frictions and costs due to swings from one year to the next. Even for strategies that completely skip vintage years (zero allocations), however, we find only limited gains to commitment timing unless the investor were willing to skip the vast majority of all vintages—a policy likely inconsistent with any long term program to evaluate and invest in private equity funds. These considerations reinforce our earlier conclusions about the potential for any substantive net gains from timing policies.

As a contrast to potential timing benefits, we find that commitment strategies that focus on fund selection provide higher performance gains than those based on vintage year timing for both buyout and venture. Giving a higher weighting to larger funds and more experienced GPs leads to higher relative performance; these effects are modest in buyouts but more substantial in venture capital.

To follow up our findings that the benefits of timing commitments are limited, we explore the time-series properties of cash flows that emerge from alternative capital allocation strategies. Our findings here highlight the importance of the commitment model for understanding private equity cash flows. We find that diametrically opposite capital commitment strategies lead to 
capital calls that are only modestly negatively correlated. These strategies result in distributions that are highly positively correlated. Thus, the thread between cash flow performance and the timing of limited partner capital commitments is frayed by the commitment process that delegates investment and exit activity to the GP.

To illustrate this further, we build benchmark returns series that invest capital in a public market index to explore the implications of different timing choices. One series mimics the patterns of capital calls and distributions actually made by GPs. A second series mimics the pattern of calls, but instead of facing endogenously determined exits, the holding periods are constant. This provides a counter-factual return series in which the endogeneity of exit, but not of initial investment, is broken. A third series further replaces the endogenous capital calls with a fixed investment schedule. Using these series we explore the performance of both buyout and venture capital funds. When we compare these strategies with an observed commitment strategy to private equity, we find low correlation in cash flows even when commitments are made on exactly the same schedule. This illustrates how the endogeneity of a general partner's timing decisions (especially exits) is central to understanding the time-series of capital calls and distributions. While the commitment fund structure in private equity can create substantial benefits for LPs tapping into GP expertise, it comes at a cost of reducing the LPs' opportunity to make timing decisions.

The paper is organized as follows. Section 2 provides a discussion of data and performance metrics and then provides direct evidence that periods of high fundraising are followed by periods of low performance. This stylized fact is, in part, the motivation behind our analysis. Then, section 3 examines different strategies for timing capital commitments to buyout and venture capital funds. In section 4 strategies that focus on fund size or GP experience are presented, as well as 
information or time-weighted returns and risks from differing commitment strategies. Section 5 explores how the timing of capital calls and distributions is correlated even when the commitments are not. Finally, section 6 concludes.

\section{Data and Empirical Approach}

The data for this study are provided by Burgiss, a global provider of data management services for the limited partner community. We use fund-level cash flows from Burgiss beginning in 1987 through September 2016. Sourcing directly from LPs, Burgiss provides a set of detailed, verified and cross-checked cash-flow histories for a nearly exhaustive sample of institutionalquality private equity funds (including buyout and venture capital). These cash flows are net of fees and profit shares (also called carried interest) paid to the GP, and thus represent the actual cash inflows and outflows earned by the limited partner. Burgiss data have been used extensively in recent academic work (see, for instance, Brown, Gredil and Kaplan (2019), Harris, Jenkinson and Kaplan (2014, 2016)). We study all funds formed around the world between 1987 (the first year with meaningful numbers of funds in the data) and 2013. In total, we have data for 1,826 buyout funds and 1,845 venture funds.

\subsection{Measuring Private Equity Performance}

First, we calculate two widely used metrics in the industry: the internal rate of return (IRR) and the investment multiple (also referred to as the multiple of invested capital, or MOIC). The former measures an LP's annualized IRR based on cash contributions and distributions, net of fees and carried interest. The IRR calculation includes the estimated value of any unrealized investments (the residual net asset value, or NAV) as a final "cash flow.” The investment multiple compares the sum of all cash contributions by investors to the sum of all cash distributions and 
the NAV, again net of fees and carried interest. Neither the IRR nor the investment multiple provides a direct way to compare investments in public and private equity.

Our preferred measure of performance is the Public Market Equivalent (PME) developed by Kaplan and Schoar (2005). This relative performance measure directly compares an investment in private equity to an equivalently-timed investment in the public equity market. The PME calculation discounts (or invests) all cash distributions and the remaining NAV at the public market total return and divides the resulting value by the similarly discounted (or invested) value of all cash contributions. The PME can thus be viewed as a market-adjusted multiple of invested capital. A PME of 1.20, for example, implies that at the end of the fund's (or portfolio's) life, investors end up with $20 \%$ more than if they had invested in the public markets. PMEs compare two ways investors can have residual equity claims on companies: LP stakes in a private equity fund or ownership of publicly traded stocks. Implicitly, PME assumes that funds not invested in private equity would be allocated to public equity markets. Despite differences between the two forms of ownership, portfolio managers increasingly see them both as forms of equity rather than as completely separate asset classes. The result has been increasing use of PMEs in both research and practice. ${ }^{4}$ We use the S\&P 500 index to proxy for the public market though are results are not sensitive to the choice of benchmark.

To convert PME into an annualized measure of excess return (over and above a public equity index), we use the Direct-alpha (Direct- $\alpha$ ) methodology of Gredil, Griffiths and Stucke (2014). ${ }^{5}$ This approach starts with the same set of cash flows used in a PME calculation, but instead of calculating PME as a performance measure, the approach finds an annual excess return (alpha)

\footnotetext{
${ }^{4}$ See Morten and Jagannathan (2015) for a theoretical justification for using PME to measure private equity performance.

${ }^{5}$ Gredil et al (2014) discuss the Direct- $\alpha$ method. Kocis et al. (2009) discuss difficulties with interpreting IRRs.
} 
which, added to the index rate, discounts the flows to a value of 1.0. This excess return measure is positive when the PME is greater than one and negative when the PME is less than one but has the advantage of being an annual excess return measure.

Prior research has found that increased aggregate capital commitments (or fund flows) to buyout and venture capital (VC) funds are related to subsequent performance, especially for VC funds. We analyze the relation between private equity fundraising and performance that we observe in our data. Similar to prior research (see Kaplan and Schoar (2005), Harris, Jenkinson and Kaplan $(2014,2016))$, we measure fund flows into the industry using capital committed to buyout and VC funds during a vintage year. This provides an (imperfect) estimate of the amount of capital available to fund deals. To compare these capital flows over a longer period of time, we deflate the annual capital commitments by the total value of the U.S. stock market (CRSP total market index) at the beginning of the vintage year. Measures are developed separately for buyout and venture. We combine all funds of a given vintage year into a single portfolio to measure (pooled) performance.

Regression results are presented in Table I. For buyout funds, Panel A shows that vintages with high fundraising have lower subsequent performance whether measured on an absolute basis (IRR and MOIC) or relative to public equity (PME). This is signaled by the significant negative coefficients on fundraising in each of the three regressions. Comparison of the results, however, shows that the impacts of fundraising are stronger for absolute performance than for performance relative to public equity. The fact that the fundraising/performance relation is weaker in buyout when using the PME measure is an indication of positive co-movement between conditions in the buyout market and public equity market. 
When we examine performance cyclicality for venture capital (Panel B), we see a highly significant relationship between fundraising and all three measures of performance. This indicates that when current fundraising in VC is high, subsequent venture performance is low, even relative to public market performance.

In summary, results in Table 1 confirm the widely held view that periods of abnormally high fundraising levels are followed by periods of low performance. The challenge is whether measures of fundraising can be constructed in real time to take advantage of this pattern. The metric used in our regressions and past research is based on the full set of vintage year observations; thus using it directly for timing decisions would require perfect foresight of future fundraising levels.

\subsection{Private Equity Commitment Strategies}

This section discusses our methods for forming commitment strategies in private equity. Each year, limited partners decide how to allocate capital to new private equity funds that are seeking commitments. The decisions involve choices about the overall exposure to private equity and about manager selection in hopes of identifying high performing funds. Since LPs are typically large institutional investors, these decisions also involve organizational frictions and costs that can arise if allocation patterns swing dramatically year to year. For instance, making low or no allocations for series of years likely makes it harder, if not impossible, to maintain relationships with and analyze seasoned GPs who raise new funds every few years. There may also be agency costs; for example, a private equity team inside a large institutional LP may be hesitant to ask for a small capital allocation when private equity markets are hot, fearing that they would lose influence inside the organization, or the ability to command larger capital allocations in the future when markets cooled down. Or, LPs may not be prepared to increase investment in 
the sector when overall fundraising is subdued, even if these conditions typically result in good returns for funds raised in such periods. Moreover, even if a timing policy were put in place, there are risks that the investor may not, in practice, stick to a plan. Our analysis considers allocation weightings in a setting where the LP can face tradeoffs between aggressively pursuing timing gains and maintaining a long-term capability in private equity investing.

We focus on private equity exposure through capital commitments to newly raised funds which buy and sell companies. This has long been the dominant route for exposure to private equity and available to LPs over our entire sample period. Recent history has seen the rise of secondary markets for private equity claims and of co-investing where LPs invest alongside a GP and thus may exert more influence on cash flow timing. These are interesting areas for research but were not routes available over much of our sample period and involve additional issues and potential costs (see, for instance, Nadauld et al. (2019), Braun, Jenkinson and Schemmerl (2019), Fang, Ivashina and Lerner (2015)). Funds-of-funds, whose holdings are the private equity funds themselves, are also channels to private equity exposure but are likely most attractive to smaller investors seeking to diversify. Funds-of-funds also involve an extra layer of fees that can erode any benefits, especially in buyout (see Harris, Jenkinson, Kaplan and Stucke (2018)).

To construct specific strategies, we begin by assuming that the set of funds raising capital in a given vintage year is known at the beginning of the year. We do this primarily for analytical simplicity and convenience, but this is not an unreasonable assumption for two reasons: (a) investors learn informally about future fundraising plans through annual meetings and other industry networking events, and (b), fundraisings typically play out over periods of many months. Another important factor is the overall amount of capital deployed over time and to any single vintage year. Large asset managers may have difficulty allocating a fixed proportion of their 
portfolio to private equity in a given year because their portfolios are so large that the capital allocation would dwarf the demand for new capital in a given year. To remove this possibility, and to keep the strategies on an equal footing in terms of the total amount of capital overall that is allocated, we assume that an average amount of $\$ 100$ per year is committed to the asset class and require each of our strategies to satisfy this scaling constraint. The simplest version of such a strategy would not try to time private equity and just allocate $\$ 100$ in each vintage year (“fixed annual commitment”).

Using this framework, we generate a range of timing strategies, each of which presents different statistical and organizational issues. At one end of the spectrum are strategies that require perfect foresight and clearly cannot be implemented by investors allocating capital in real time. Since our intention is to estimate bounds on the gains from a disciplined timing strategy for a large institutional investor we have placed limitations on swings in annual allocations. Our "foresight" strategy assumes that with complete foreknowledge of the future performance of subsequent vintage years, an investor allocates $\$ 200$ per year in years with above median performance and $\$ 0$ per year in the other half of the years. In addition to a foresight strategy, we also construct an "antiforesight” strategy which invests $\$ 200$ in the bottom half of the years and $\$ 0$ in the better half. Figure 1 illustrates time-series of commitments for these strategies. In practice, some investors have changed their private equity allocations over time quite dramatically. For instance, CalPERS is one of the largest investors in private equity and, as a public pension fund, is required to reveal the commitments it makes each year. These have varied considerably over time. CalPERS committed a total of $\$ 27$ billion to private equity funds over the two-year period 2007-2008, but only $\$ 2.2$ billion from 2009-2010. This is nearly as extreme as the 'double or nothing' strategy that we model and is driven by many factors—not just timing. 
Other possible timing strategies may be feasible in a statistical sense (e.g. not requiring foresight), but still difficult to implement organizationally because they entail large swings in annual allocations. We devise a set of strategies based on observable conditions in the private and public markets (and thus feasible statistically) and that constrain swings in annual allocations (thus reducing organizational challenges). Given the research findings of a negative relationship between fundraising and subsequent performance, our approach identifies vintage years with "high" or "low" fundraising levels. We create four alternative ways to gauge fundraising that could be identified by investors (without foresight) and use these to adjust vintage year allocations. The first measure compares annual fundraising to recent fundraising levels. We compute three-year rolling average levels of fundraising, separately for buyout and venture capital, and commit more or less capital to a given vintage year based on how current fundraising compares to this trend. As a pro-cyclical measure, we compute the ratio of the current year total fundraising amount to the average value of the previous 3 years and allocate an amount equal to $\$ 100$ times that ratio. For example, if the vintage year's ratio is 1.3 , then we allocate $\$ 130$ to that vintage year in the procyclical strategy and $\$ 70(\$ 70=\$ 200-\$ 130)$ in the counter-cyclical strategy. We cap the maximum annual commitment at $\$ 200$ and scale the time series of pro-cyclical allocation ratios so it averages 1.0 over our sample period. ${ }^{6}$ Using this approach, Figure 2 depicts the pattern of capital allocations for buyout, and Figure 3 depicts the pattern for venture capital. These patterns involve allocation swings over time but continue to make commitments to each vintage year.

Our second measure scales fundraising over a longer term using the size of the public stock market. To do this, for each vintage year we form a ratio of fundraising to the level of the stock

\footnotetext{
${ }^{6}$ Because these ratios will not generally average to 1.0 , we rescale them with respect to the values based on average ratios for the full sample. Rescaling allows us to consider average commitment amounts that are the same (e.g., \$100) across different strategies. This adjustment generates a look-ahead bias beyond the current year, but this rescaling effect is small and does not affect the interpretation of ourresults.
} 
market. ${ }^{7}$ We then scale this by computing a dynamic, backward-looking average of that ratio from the prior year back to 1980 . Thus this method uses data from periods prior to the allocation decision. We use the same proportional adjustments of allocations as for our first measure and set a maximum annual commitment of $\$ 200$.

Our third and fourth timing measures follow the same general procedure for determining vintage year allocations (separately in buyout and venture) but use "dry powder" (the sum of all capital committed to GPs but not yet called from Burgiss data) rather than the annual level of fundraising. The third timing measure scales dry powder by its rolling three-year average. The fourth is similar but scales dry powder by the total net asset value of all active funds. We compare the current year's ratio to those from the past, using a dynamic, backward-looking average starting in 1981, our earliest year of dry powder data. Later in the paper we consider other investment strategies to test for sensitivity.

\section{Performance Results for Market-timed Commitment Strategies}

\subsection{Timing Strategies for Buyout Funds}

Panel A of Table II displays the long-run portfolio performance results from timing strategies in buyout. The fixed annual commitment strategy provides a PME of 1.15 and Direct- $\alpha$ of 2.8\%, indicating outperformance relative to public equities. The strategy's IRR is $16.5 \%$ with a multiple of paid-in capital of 1.80. These findings echo earlier research showing that buyout funds have outperformed a broad public market index (e.g. Harris, Kaplan and Jenkinson (2014)).

A fixed annual allocation provides a useful reference point and is easy to implement. At the other extreme are strategies that require foresight. Doubling the capital allocated to above-median

\footnotetext{
${ }^{7}$ We use the CRSP total market index to measure the value of the US stock market and Private Equity Analyst for that year's fund raising. PEA is a widely distributed monthly trade publication produced by Dow Jones and tracks US fundraising activity in the private equity markets.
} 
vintage years (based on pooled PME) and allocating nothing to below-median vintage years boosts the PME to 1.35, while the anti-foresight strategy (the opposite pattern of capital allocation over time) reduces it to 0.97 . The corresponding Direct- $\alpha$ figures are $7.4 \%$ and $-0.6 \%$, respectively. The foresight IRR is $21.4 \%$ with a MOIC of 1.94 , but the anti-foresight IRR and multiple fall to $13.4 \%$ and 1.65 , respectively.

Looking at these foresight strategies sets a range for possible gains if a LP could avoid underperforming vintage years. Compared to the PME of 1.15 if capital is committed equally across all years (the fixed commitment), the foresight strategy's PME offers a possible upside in PME of $0.20(0.20=1.35-1.15)$ and corresponding benefits in the other performance metrics.

The next four sets of results in Panel A are for feasible timing strategies. As discussed earlier, each strategy is based on a measure to gauge whether a particular vintage year appears to be an abnormally high or low year in terms of the fundraising cycle. These signals lead to commitment strategies: a pro-cyclical strategy over-weights high fund-raising years, while a counter-cyclical strategy over-weights low fund-raising years.

Rows 4 and 5 report results when commitments are adjusted based on the year's fundraising activity relative to the previous 3-year average. These results indicate a timing gain for PME of 0.05 relative to the fixed annual commitment strategy: specifically, the counter-cyclical strategy provides a PME of 1.20 (0.05 higher than the fixed strategy) and the pro-cyclical strategy provides a PME of 1.10 (0.05 lower than the fixed strategy). The differences in Direct- $\alpha$, IRR and MIOCs are also consistent with gains to a counter-cyclical strategy in buyouts.

Rows 6 and 7 reflect scaling fundraising by the value of the stock market. Timing gains are similar to those when scaling is by recent fundraising. The counter-cyclical strategy provides a PME of 1.17 and the pro-cyclical strategy's PME is 1.09. 
The next two sets of rows turn to dry powder to drive allocation strategies. When dry powder is weighted by its recent levels, the performance statistics looks very similar to those from strategies using fundraising levels. At least in our data, the two measures provide very similar allocation strategies. Weighting dry powder by the net asset value in funds produces smaller differences between the pro-cyclical and counter-cyclical strategies than does weighting by recent levels.

Overall, our "foresight” results for buyout suggest potential timing gains in both absolute performance (IRR and MOIC) and performance relative to public equity markets (PME and Direct- $\alpha$ ). However, attempts to exploit these benefits in real time based on observable patterns in the fundraising cycle provide modest benefits, less than a third of the magnitude suggested by foresight strategies.

\subsection{Timing Strategies for Venture Capital Funds}

Panel B of Table II reports analogous results for venture capital. The fixed allocation strategy provides a PME of 1.54 and robust values for the other metrics, in line with substantial wealth creation over the last quarter century of VC investing history.

A foresight strategy that doubles allocations to above-median vintages and that has no exposure to below median vintages generates strong relative performance (PME of 1.84) and leads to substantial increases in the other metrics. The anti-foresight strategy's PME is 0.99 with similarly dramatic reductions in all performance metrics. Compared to buyout (Panel A), the larger potential for gains in VC reflects the higher variability over time of returns in VC compared to buyout. This shows up, for instance, in the higher sensitivity of VC returns to capital flowing intothat sector as demonstrated by regressions in Table I. 
The next four sets of rows of Panel B of Table II show results of pro-cyclical and countercyclical strategies in VC. Using fundraising scaled by its recent levels, the first pair of rows reveals a counter-cyclical PME of 1.43, while the pro-cyclical PME is 1.62. The other performance measures are also lower for the counter-cyclical strategy. As a result, and perhaps surprisingly, simply relying on recent fundraising to scale timing measures actually makes counter-cyclical investing in VC look slightly worse. If fundraising is scaled by the value of the stock market, the next two sets of rows show essentially no timing gains in terms of PME. There is, however, a modest advantage in absolute performance; the counter-cyclical strategy provides an MOIC of 2.59 compared to 2.39 for the pro-cyclical allocations.

The final two sets of rows in Panel B turn to measures based on dry powder. When dry powder is scaled by recent levels of dry powder, the pro-cyclical and counter-cyclical strategies provide very similar performance (e.g., a spread of only 0.03 in PME). Weighting dry powder by net asset values, the counter-cyclical strategy outperforms pro-cyclical allocations on all measures but the improvements still fall far short of the potential gains shown in the perfect foresight strategies.

Overall, the potential timing gains in VC shrink to less than a fourth of the apparent gains (from perfect foresight) once we use strategies that could be implemented. Moreover, some of our timing measures send different signals on whether a counter-cyclical strategy is useful, complicating any attempt to adopt timing in practice. The patterns in Panel B reflect the difficulty in predicting market peaks ex ante; for example, 1997 and 1998 looked like fundraising peaks for venture capital from a historical standpoint, but were eclipsed by fundraising in 1999 and 2000, which made counter-cyclical strategies benchmarked against recent fundraising levels scale back too soon from an ex post perspective. 
Overall, the results in Table II suggest that operational strategies to time commitment strategies in buyout and venture capital based on private equity market conditions (e.g. fundraising or dry powder levels) will find difficulty in creating substantive performance benefits.

\subsection{Additional tests for the effects of timing capital commitments}

We also conducted additional test using different approaches for allocation adjustments. In the case of buyouts, we used the average multiple of EBITDA (from SDC Platinum) paid in buyout transactions during a year as an alternative measure of market conditions. Allocation strategies based on these multiples compared to past levels lead to very modest differences between pro-cyclical (high multiples) and counter-cyclical strategies; a PME difference of only 0.07 , which is smaller than the difference resulting when we use dry powder scaled by its recent levels which was reported earlier in Table II.

In another set of tests, we adjusted assumptions on weighting allocations to allow for more extreme variation in vintage year allocations. These changes might improve timing benefits but exacerbate organizational problems in maintaining a long term capability in private equity investing. First, we relaxed the constraint of a maximum allocation of \$200 in one year and did not scale the allocation weights to sum to one (which would have guaranteed an average commitment of $\$ 100$ ). The effects of these adjustments on timing benefits were minor. To illustrate, Table III compares results when we scale fundraising by the value of the stock market. The first two rows replicate the figures in Table II using our earlier scheme of weighting. The second set of rows makes the adjustments and allows for more extreme variations in allocations. Results for all four performance measures are very similar between the two sets of weightings for both buyout (Panel A) and venture capital (Panel B). 
Table IV goes a step further and illustrates a "binary cyclical" approach to "avoid high fundraising years” altogether. This counter-cyclical strategy skips vintage years (assigns a zero allocation) if the fundraising metric in that year exceeds a threshold multiple of its historical average, and invests $\$ 100$ in all other years. We use fundraising scaled by the stock market as done in Table III. We consider thresholds set at 1 times, 1.5 times, 2 times and 2.5 times the historical average fundraising level. For instance, if $X=1.5$ the “avoid high funding years” strategy would be to allocate nothing to any vintage year which has fundraising more than 50 percent higher than the historical average. For buyout, the column headed $X=1.5$ provides an interesting comparison since that threshold value splits the sample years in roughly half; the strategy to avoid the high fundraising years commits capital to 14 out of the 27 vintage years in our sample period. The PME of 1.21 for avoiding the high fundraising years is essentially the same as PMEs for the counter-cyclical buyout strategies in Table II. Interestingly, the $\mathrm{X}=2.5$ threshold shows the clear problems of investing in high fundraising years. If one took the approach of only allocating to high fundraising vintages, this pro-cyclical "invest only in high years" strategy has a PME= 0.92; however, only five of 27 years qualify as "high" at this threshold. Avoiding those five years, creates a PME of 1.24 at $X=2.50$ providing only a small boost from PMEs at lower thresholds.

Turning to venture capital, results in the lower part of Table IV again illustrate the difficulty of implementing a timing strategy in real time. For $\mathrm{X}=1.0$ it appears better to invest in high funding years, echoing results from some pro-cyclical strategies shown in Table II. For $\mathrm{X}=1.50$ there are modest PME gains from avoiding high fundraising years but only five years are deemed high fundraising. Once $\mathrm{X}=2.0$ only two vintage years qualify as high fundraising in VC.

Overall our additional tests confirm the rather limited benefits of trying to time commitments. Moreover, the strategies often lead to large swings in allocations that may create 
substantial organizational issues for large institutional investors with a long term plan for private equity investing.

\subsection{Diversification and the number of funds in the portfolio}

To focus on timing, the previous analysis uses commitment strategies assuming an LP can commit to all funds in a vintage year. In practice, LP portfolios will not commit to all funds that are fundraising at a given point in time. To explore the implications of this limitation, we simulate the performance assuming an LP randomly selects a given number of funds each year. Figure 4 shows the distribution of simulated PMEs from a fixed annual capital commitment across vintage years for different numbers $(\mathrm{N})$ of funds in each year's portfolio.

Panel A shows results from 10,000 simulations for buyout funds. The distribution of PMEs narrows appreciably as funds are added. For example, for $\mathrm{N}=7$, the standard deviation is only 0.04 , much reduced from 0.12 when $\mathrm{N}=1$. For VC funds (Panel B), the results are much more dispersed than for buyout funds, as would be expected given the larger range of performance among individual VC funds. For $\mathrm{N}=7$, the standard deviation is 0.14 , down from 0.36 for $\mathrm{N}=1$ but still quite large compared to buyout. For both buyout and VC funds there are meaningful continued reductions in the standard deviation of simulated portfolio returns as the number of funds increases to $\mathrm{N}=15$ and $\mathrm{N}=30$. We repeated all simulations weighting funds equally rather than by fund size. The patterns in standard deviation are quite similar. Despite the variation in possible performance due to a limited number of funds, almost all realizations have a PME great than 1.0 for portfolios with 5 or more funds (for both buyout and venture).

Overall, Figure 4 suggests that the previous buyout results would generally fit the experience of LPs even if they had more limited portfolio sizes. For venture, deviations from the previous results could be substantial once LPs try to implement them with limited portfolio sizes. In 
practice, these deviations would be even more pronounced if an LP cannot select funds randomly but is denied access to certain funds, which are likelyhigh performing. Thus, in the case of venture funds, LPs likely benefit more from fund access and manager selection skills than from attempts to time aggregate commitments.

\section{Performance Results for Strategies Not Based on Timing the Market}

\subsection{Variations of a Fixed Annual Commitment}

Table V explores other strategies that do not explicitly try to time the market. We focus on PME, our preferred performance measure. The first row of Panel A repeats the base-line case of fixed annual commitments from Table II. For buyout (the first column of numbers), comparison of the first two rows shows that when making fixed annual commitments, it makes little difference in the PME (1.13 versus 1.15) whether one uses equal- or value-weighting of funds. The third row shows results from growing the annual commitment at 5 percent (to approximate anticipated portfolio growth) and again provides a similar PME (1.16) for buyout. Finally, the fourth row simply has the LP adjust commitments in proportion to the level of annual fundraising. Again, the PME is similar (1.14).

The second column of numbers in Table $\mathrm{V}$ tracks strategies for commitments to venture. Unlike buyout, there are marked differences across some of the strategies in Panel A. Equal weighting of funds in a given vintage year (second row) reduces PME to 1.37 versus 1.54 for value-weighting of fund commitments (first row). In contrast, the strategy of growing commitments at a constant rate (third row) provides a PME similar to that of the fixed value-weight strategy. Adjusting commitments in line with venture fundraising (fourth row) creates a sharply lower PME (1.20) as a consequence of loading up on under-performing vintage years. 
Thus, for venture, the PMEs in Table V suggest that some form of smoothing commitments over time is beneficial. Simply following the market cycles of fundraising to trigger commitments likely reduces performance. Moreover, within venture, weighting larger funds more heavily has provided performance benefits in the past. While operationally feasible strategies to proactively time venture commitments are hard to identify (as shown in Table II), some form of dollar averaging across years seems appropriate.

\subsection{Strategies based on GP Experience}

The first set of rows in Panel B of Table V explores allocations based on GP experience, not timing. In each year, we partition funds into those being raised by "experienced GPs" and "new GPs” (inexperienced). Managers are classified as experienced if they have raised at least two prior funds within the same asset class (buyout or VC). We then track a fixed annual commitment strategy using either only experienced or only new GPs.

For buyout, the “experienced GP” strategy provides a higher PME, suggesting modestly better performance for experienced GPs in the buyout space. For venture, the experienced GP strategy has a much higher PME (1.71) than the new GP strategy (1.15); moreover, the gap in venture is much larger than in buyout. The findings suggest that GP experience is more important for picking venture funds than buyout funds. This suggests that the skills for venture investing may be harder to learn or replicate than for buyout investing. GP experience may be a proxy for manager ability in that the GP is able to raise additional funds based on a track record of prior funds.

\subsection{Strategies Based on Fund Size}

The second set of rows in Panel B of Table V focuses on allocations based on fund size. We partition funds on size, separately for buyout and venture. Large funds are those obtaining capital committed in excess of the median of all funds from the vintage year; other funds are classified as small. For 
buyout, the large fund strategy has a higher PME than for small funds, a 0.07 difference between the two groups. The gap is substantially larger for venture with a PME advantage of 0.34 for large versus small funds. The more pronounced effect for venture echoes earlier results showing that VC strategies that value-weight within vintage years provide higher PMEs than equal-weighting strategies.

In summary, for venture investing there appears to be appreciable performance advantages to committing capital to more experienced GPs and larger funds. This is consistent with the potential gains from strategies for manager selection (e.g., picking top quartile funds in VC as illustrated in Harris, Jenkinson and Kaplan (2016)). In practice, whether such strategies are implementable likely depends on the LP. For instance, venture funds raised by experienced top-performing GPs may limit access to a small set of previous investors. In buyout, the potential performance gains from focusing on GP experience or fund size are much smaller. The findings reinforce research showing the more valuable role of fund selection and access in venture investing.

\subsection{Time-weighted Returns, Volatility, and Sharpe Ratios}

PME measures value creation compared to a public market alternative. Importantly, PME is quite different from time-weighted returns that are often used to measure performance in public stocks. Investors in public markets can readily control the timing of cash flows through purchases and sales, unlike the situation in private equity. Once a LP makes a commitment, the timing of a fund's cash flows is largely determined by the GP. Moreover, an LP cannot readily sell partnership claims due to the lack of liquidity in private equity. For this and other reasons, time-weighted returns are problematic performance measures for private equity. Nonetheless, time-weighted returns are often used in practice to try to gauge the returns and risk of private equity relative to 
other assets. In this section, we examine what signals such time-weighted returns provide relative to our earlier findings.

Table VI revisits commitment strategies from Table V, adding the average annual return, volatility and Sharpe ratio based on time-weighted returns. For buyout, the second column of Panel A shows that average returns are lower for equal-weighting of funds within vintage years (row 2) than for value-weighting (row 1). Equal-weighting results in lower volatility and, as a consequence, a slightly higher Sharpe ratio. However, a t-test comparing the returns for row 1 (value-weighting) and row 2 (equal-weighing) shows no significant difference in the two return series. Similarly, there are not significant differences between the annual return for the fixed allocation from row 1 and returns from any of the other strategies that commit across all buyout funds (rows 2 through 4).

The last four rows of Panel A report on variants of the fixed allocation strategy which focus on subsets of buyout funds. Focusing commitments on experienced GPs provides a mean annual return of $16.0 \%$ (row 6), higher than for new GPs (row 7) and is accompanied by a higher Sharpe ratio. This advantage to experienced GPs mirrors PME findings. However, a paired $t$-test comparing returns for the experienced GP strategy (row 6) with the simple fixed strategy (row 1) results in a $t$-statistic of only 1.66. The last two rows of Panel A show that the large buyout fund strategy has a higher mean return $(14.9 \%)$ than does a small fund strategy but it is very close to the 14.5\% mean for the simple fixed value-weighted strategy (in the first row).

For venture, Panel B of Table VI shows that equal-weighting within vintage years reduces mean returns compared to value-weighting, as it did in buyout. Unlike buyout, the difference is statistically significant; testing the paired differences between returns from the first two rows results in a $t$-statistic of 4.23 . The other strategies for venture which commit to all funds (rows 3 
and 4) produce essentially the same mean returns and none are significantly different from the fixed annual strategy (row 1) based on a paired $t$-test of returns. Volatility is similar among the venture strategies. Not surprisingly, volatility for venture strategies is much higher than volatility for buyout (reported in Panel A). These high volatilities result in Sharpe ratios that are lower for VC than buyout.

The bottom four rows of Panel B show that mean returns mirror differences in PMEs: committing to experienced venture GPs provides higher returns than committing to new GPs, and committing to large venture funds provides higher returns than committing to small venture funds. The return differences in venture based on GP experience and fund size are higher than in buyout and are also statistically different.

\section{The Timing of Cash Flows from Different Commitment Strategies}

The results thus far indicate that private equity investing leads to higher returns compared to public equity, confirming earlier research findings. Such relative outperformance flows from a private equity fund structure which allows the LP to take advantage of GP specialization in buying, managing and selling companies. At the same time, however, our findings show that there are limited performance gains from implementable strategies to time private equity commitments. A key complication for these strategies, as noted earlier, is that private equity fund structures mean that the actual cash flows resulting from investor (LP) commitments are determined by GPs. Thus, quite different commitment strategies might produce cash flow patterns (calls and distributions) that are themselves not as different. This section explores the cash flow properties of alternative commitment timing strategies to examine effects of the endogenous investment (call) and exit (distribution) decisions made by GPs. 
To illustrate the disconnection between the timing of commitments and cash flows, we examine the capital calls and distributions from three different commitment strategies: fixed, procyclical, and counter-cyclical based on annual fundraising. Figure 5 plots results for buyout funds. Panel A shows that cash calls cluster over time even for the negatively correlated commitments made by pro-cyclical and counter-cyclical allocation strategies. Even more obvious is the strong positive correlation across distributions from all three strategies shown in Panel B. For instance, the correlation of distributions between the pro-cyclical and counter-cyclical strategies is 0.81 , even though the commitments are negatively correlated. In short, the timing of cash distributions from different allocation strategies are likely to be very similar for buyout funds as funds from nearby vintages respond to the same market-wide investment and exit opportunities. This result echoes earlier research showing that exits from buyout funds are highly cyclical (Robinson and Sensoy, 2016).

Figure 6 plots results for venture funds. The correlation of calls for the pro-cyclical and counter-cyclical allocations in venture are lower than for buyout, but capital distributions are again positively correlated. In fact, the distributions are very similar across vintage years for the pro- and counter-cyclical strategies with the notable exceptions of 1999 and 2000, when the pro-cyclical (and fixed) distributions are much higher than for the counter-cyclical allocation strategy. This short window also explains why our earlier performance results found that this counter-cyclical plan underperforms the pro-cyclical strategy in venture: the counter-cyclical strategy dialed back allocations too quickly in the 1990s and was underweighted in the exceptionally good vintages in the late 1990s.

Overall, the plots of contributions and distributions presented in Figures 5 and 6 reinforce the idea that GPs tend to exit investments in a highly correlated manner even when capital was 
committed with quite different weights to individual vintage years. In general, strategies with very different capital commitment patterns result in only mildly negatively correlated capital calls and positively correlated distributions, as GPs pursue market-wide opportunities to buy and sell companies.

To explore the timing of cash flows in more depth, we contrast the performance of private equity with hypothetical strategies of investing in public equity. This allows us to see the effects of changing timing decisions from those made by GPs. By construction, any such public equity strategy earns the public return over periods in which it invests and thus has no relative performance advantage to public equity (and as a result has a PME of 1.0 and Direct- $\alpha$ of zero). Such strategies can, however, have quite different absolute performance and patterns of distributions depending on how they time purchases and sales.

For a series of strategies, Table VII reports information on the distributions to LPs, absolute performance (IRR, MOIC), the remaining net asset value at the end of our sample period and how the distributions are correlated to the observed pattern of distributions from investing in private equity. These figures highlight both the level of performance as well as how the time series properties of distributions change as timing assumptions are altered. The first row depicts the fixed commitment strategy of investing in private equity (as reported earlier in Table II). Row two is based on a hypothetical portfolio that invests in public equity (SP500) and mimics GP timing on calls and distributions. One way to think of this portfolio is as a fund set up by a money manager who invests only in the public market index. The fund structure is designed so that the investor (LP) makes a capital commitment to the manager who then has decision rights on when to call and distribute capital. Even though investing in public equities, the manager times purchases (calls) and sales (distributions) by looking at what GPs in private equity are doing. The manager calls 
funds at the same time and at the same percentage of commitments as do GPs, and distributes money when GPs do at the percentage of NAV distributed by GPs The fund thus mimics the timing of GPs but by definition would always earn the public market return on all investments. At any point in time, the NAV of this portfolio is the accumulated value of all capital calls (at the public market return) adjusted downward for any distributions. The remaining rows in Table VII show strategies that, in stages, decouple timing decisions from those made by GPs.

Panel A focuses on buyout. The $16.5 \%$ return (IRR) from investing in private equity (row 1) is over 200 basis points higher than a public equity strategy return of $14.0 \%$ (row 2) from exactly mirroring GP cash flow timing. This spread illustrates the positive relative performance (e.g., Direct- $\alpha$ reported earlier ${ }^{8}$ ) of the fixed commitment strategy and is consistent with prior research that buyout funds have outperformed public equity (e.g. Harris, Jenkinson and Kaplan (2014), Robinson and Sensoy (2016)). The higher returns show up directly in cash benefits: quarterly distributions from private equity (mean of 35.44) are 20\% higher than for the public strategy (29.42) with comparable variability quarter to quarter. ${ }^{9}$ The distribution series in rows 1 and 2 are very highly correlated since they share the same GP timing of calls and distributions.

The final three sets of rows in Panel A examine how adjustments away from GPs' actual timing decisions affect cash distributions and performance. One set of strategies mimic GP timing

\footnotetext{
${ }^{8}$ The assumption made in row two is to distribute cash as a percent of net asset value in the same proportion as GPs do. This is in order to avoid the potential of making a distribution in excess of the value of the portfolio. That result, and hence a short position in the public index, might occur if private equity distributions were large based on private equity returns which were not achieved in public markets. As a consequence, this is a slightly different assumption than goes into a direct alpha calculation. That said, the two approaches provide very similar results in terms of the relative outperformance of private over public equity in our sample.

${ }^{9}$ To understand the scale of these numbers, recall that a fixed $\$ 100$ per year is being committed. We obtain very similar figures and the same conclusions if we equally weight funds rather than value weight. As a comparison, the $14 \%$ return shown in row 2 is slightly higher than the 13.7\% IRR from a cruder "dollar averaging" timing assumption of investing 100 a year in public equity (all invested immediately) and holding for five years. The absolute return is, however, notably higher than the $9.1 \%$ return from a simple buy and hold strategy in public equity over our sample period.
} 
of capital calls but adopt a fixed length investment period, thus decoupling the timing of sale from the time series variation in GP exit decisions. We consider three holding periods: 3 years, 5 years, and 7 years, spanning the range of average holding periods often cited for GP investments. These strategies result in smaller cash distributions than we observe for buyout and come with higher variability for the longer horizons. Moreover, the IRRs remain well below buyout returns for all horizons and are lowest for the seven-year horizon. The main result, however, concerns the correlation between the distribution series and the actual buyout series: at the three-year holding period, the correlation is 0.35 and correlations fall to 0.17 at the five-year horizon and 0.22 at the seven-year horizon. Thus, strategies that exactly match both the amount and timing of capital commitments and the endogenous timing of GP capital calls but miss the endogenous timing of exits generate distributions that have low correlation with the actual distribution series experienced by buyout fund investors, even if the holding period roughly matches the average holding period for the asset class. This stands in stark contrast to the high correlations of distribution series from pro-cyclical and counter-cyclical commitment strategies to buyout (and hence subject to GP exit timing) shown in Figure 5.

The final two sets of public equity strategies in Panel A exogenously set both the timing of investment and the holding period; they thus remove the time series variation in GP behavior on both calls and distributions. We show results for two different schedules of investment. The first follows the average we observe in the data: $30 \%$ of committed capital in the first year, $20 \%$ in year $2,18 \%$ in year $3,12 \%$ in year 4 , and $10 \%$ in year 5 . The second calls (invests) capital in equal installments over five years. Again, the strategies result in smaller distributions than for buyout except for the seven-year horizon over which they are roughly the same. The higher MOIC for the seven-year holding period, reflects a longer holding period than appears implicit in the 
buyout series; the IRR for that seven-year strategy is $14.1 \%$ well below that of buyout and essentially the same as for the public investing series that mimics GP timing (row 2). What stands out again in the figures is the reduction in correlation of distributions with those from buyout which is 0.24 at the seven-year horizon as shown in the last row of Panel A.

Turning to venture capital, the first two rows of Panel B display the pronounced relative outperformance of investing in VC versus public equity-echoing earlier results. As shown in row 2, a strategy of investing in public equity and mimicking timing decisions from venture capital GPs leads to an IRR of $14.9 \%$, well below the VC IRR of $29.1 \%$ from row 1 . The actual quarterly distributions from VC (mean of 47.04) are substantially larger than for buyout (Panel A) but the volatility of distributions is over four times as high. This reflects how dramatically venture capital exit opportunities vary with market conditions. Likewise, all the strategies of investing in public equity provide much smaller and less volatile distributions than the actual VC series. Notably, the correlations of the public strategies with venture capital distributions are generally higher than they are for buyout strategies, ranging from 0.45 to 0.69 and reflecting the importance of aggregate market conditions for exit in venture capital. High correlation is consistent with high market valuations disproportionately favoring strong VC exits, and at the same time, high market valuations coinciding with strong realizations of the fixed holding-period benchmarks in public equity. This is consistent with the higher return from a public investing strategy that mimics GP timing in VC (IRR of 14.9\%, row 2 of Panel B) versus buyout (IRR of 14.0\%, row 2 of Panel B).

Overall, our results illustrate how the thread between performance and an investor's timing of capital commitments is frayed by a commitment model which delegates investment and exit activity to the fund manager; diametrically opposite capital commitment strategies can lead to capital calls that are only modestly negatively correlated and distributions that are highly positively 
correlated. While commitment fund structure creates substantial benefits for LPs tapping into GP expertise, it comes with a reduction in the LPs opportunity to time investing.

\section{Summary and Conclusions}

Due to a lack of accurate and comprehensive historical data on fund-level cash flows, little is known about the practical aspects of investing in private equity across market cycles. Yet these practical issues have important implications for our understanding of the institutional structure of this market as well as the liquidity properties of the asset class. Unlike public markets in which assets (e.g. stocks) can typically be purchased or sold almost immediately, limited partner investors who commit capital to private equity funds face significant delays and uncertainty about the timing of purchases and sales which are controlled by the general partner. As a consequence, there is substantial 'commitment risk': the investor has pledged capital but does not control the timing of when the money is put to work or returned.

This paper explores, in the context of this commitment risk, limited partners' ability to protect themselves against downturns in private equity performance that come on the heels of strong periods of fundraising in the industry. Using comprehensive Burgiss data from over 3,500 private equity funds going back to the 1980s, we create the full series of cash flows and net asset values that an LP would have experienced for a variety of capital commitment strategies. This allows us to explore if 'commitment timing' based on market cycles can improve performance.

In buyout, hypothetical timing strategies that rely on perfect foresight of the future suggest potential timing gains in both absolute performance and performance relative to public equity markets. However, attempts to exploit these benefits in real time based on observable patterns in the fundraising cycle provide modest benefits, less than a third of the magnitude suggested by foresight strategies. In venture capital, there is more room for commitment timing to affect 
performance, but at a practical level, it is difficult, if not impossible, to do so. These finding suggest that devoting substantial limited partner resources to timing private equity commitments based on fundraising conditions leads, at best, to modest performance improvements. Moreover, these have to be weighed against organizational costs and frictions that allocation swings may be pose for maintaining a long-term capability in private equity investing. Our findings also suggest that selection strategies focusing on fund and manager characteristics appear to provide more potential for enhanced performance than does commitment timing.

Investigating the time patterns of cash flows highlights the importance of commitment risk: diametrically opposite capital commitment strategies lead to capital calls that are only modestly negatively correlated, and in turn to distributions that are highly positively correlated. Thus, the thread between performance and the timing of limited partner's capital commitments is frayed by the commitment process associated with delegating investment and exit activity to the general partner. These findings call for more work understanding how the nature of delegation in private equity affects the performance and liquidity properties of the asset class. 


\section{References}

Braun, Riener, Tim Jenkinson and Christoph Schemmerl, 2019, Adverse Selection and the Performance of Private Equity Co-investments, forthcoming Journal of Financial Economics.

Brown, Greg, Robert Harris, Tim Jenkinson, Steve N. Kaplan and David Robinson, 2015, What Do Different Commercial Data Sets Tell Us About Private Equity Performance?, Working Paper, Private Equity Research Consortium. SSRN paper 2706556.

Brown, Gregory, Oleg Gredil and Steven N. Kaplan, 2019, Do Private Equity Funds Manipulate Reported Returns? forthcoming Journal of Financial Economics.

Cornelius, Peter, 2011, International Investments in Private Equity: Asset Allocation, Markets, and Industry Structure (Academic Press, London,UK).

Driessen, Joost, Tse-Chun Lin, and Ludovic Phalippou, 2012, A New Method to Estimate Risk and Return of Non-traded Assets from Cash Flows: The Case of Private Equity Funds, The Journal of Financial and Quantitative Analysis 47(3), 511-535.

Fang, Lily, Victoria Ivashina and Josh Lerner, 2015, The Disintermediation of Financial Markets: Direct Investing in Private Equity, Journal of Financial Economics 116(1), 160-1778.

Ferson, Wayne and Haitao Mo, 2016, Performance Measurement with Selectivity, Market and Volatility Timing, Journal of Financial Economics 121, 93-110.

Gredil, Oleg, 2015, Market-Timing and Agency Costs: Evidence from Private Equity. Working Paper, Tulane University.

Gredil, Oleg, Barry Griffiths and Rudiger Stucke, 2014, Benchmarking Private Equity: the Direct Alpha Method, SSRN paper 2403521.

Harris, Robert, Tim Jenkinson, and Steven N. Kaplan, 2014, Private Equity Performance: What Do We Know? Journal of Finance 69(5), 1851-1882.

Harris, Robert, Tim Jenkinson, and Steven N. Kaplan, 2016, How Do Private Equity Investments Perform Compared to Public Equity? Journal of Investment Management 14(3), 1-24.

Harris, Robert, Tim Jenkinson, Steven N. Kaplan, and Rudiger Stucke, 2015, Has Persistence Persisted in Private Equity? Working paper, University of Chicago. SSRN paper 2304808.

Harris, Robert, Tim Jenkinson, Steven N. Kaplan, and Rudiger Stucke, 2018, Financial Intermediation in Private Equity: How Well Do Funds of Funds Perform? Journal of Financial Economics 129(2), 287-305.

Kaplan, Steven N., and Antoinette Schoar, 2005, Private Equity Returns: Persistence and Capital Flows, Journal of Finance 60(4), 1791-1823. 
Kaplan, Steven N., and Berk Sensoy, 2015, Private Equity Performance: A Survey, Annual Review of Financial Economics 21(11), 1-18.

Kaplan, Steven N., and Per Stromberg, 2009, Leveraged Buyouts and Private Equity, Journal of Economic Perspectives 23(1), 121-146.

Kauffman Foundation, 2012, We Have Met the Enemy. . . And He is US: Lessons from Twenty Years of the Kauffman Foundation's Investment in Venture Capital Funds and The Triumph of Hope over Experience, White Paper.

Kocis, James M., James C. Bachman, Austin M. Long, and Craig J. Nickels, 2009, Inside Private Equity (John Wiley \& Sons, Hoboken, N.J., USA).

Lerner, Josh, Antoinette Schoar, and Wan Wongsunwai, 2007, Smart Institutions, Foolish Choices? The Limited Partner Performance Puzzle, Journal of Finance 62(2), 731- 764.

Meads, C., N. Morandi and A. Carnelli, 2016, Cash Management Strategies for Private Equity Investors, Alternative Investment Analysts Review, Quarter 1.

Nadauld, Taylor, B. Sensoy, K. Vorkink and M. Weisbach, 2019, The Liquidity Cost of Private Equity Investments; Evidence from Secondary Market Transactions, Journal of Financial Economics, Vol. 132, No. 3, 158-181.

Robinson, David T. and Berk Sensoy, 2016, Cyclicality, Performance Measurement and Cash Flow Liquidity in Private Equity, Journal of Financial Economics, 122(3), 512-543.

Sensoy, Berk, Yingdi Wang, and Michael Weisbach, 2014, Limited Partner Performance and the Maturing of the Private Equity Market, Journal of Financial Economics 112(3), 320-343.

Sorensen, Morten, and Ravi Jagannathan, 2015, The Public Market Equivalent and Private Equity Performance, Financial Analysts Journal 71(4), 43-50.

Stafford, Erik, 2015, Replicating Private Equity with Value Investing, Homemade Leverage, and Hold-to-maturity Accounting, Working paper, Harvard Business School. 
Figure 1. Capital Commitments to Foresight Strategies for Buyout and Venture

This figure provides the capital commitment schedule for the "foresight" strategies for buyout funds and venture capital funds. The commitment is two times that in the fixed commitment strategy for vintage years where the pooled fund PME is above the median, and zero in other years. 2013 has a 1.0 (100\% of fixed) allocation to even out overall contributions because of the odd number of vintage years in the sample period.

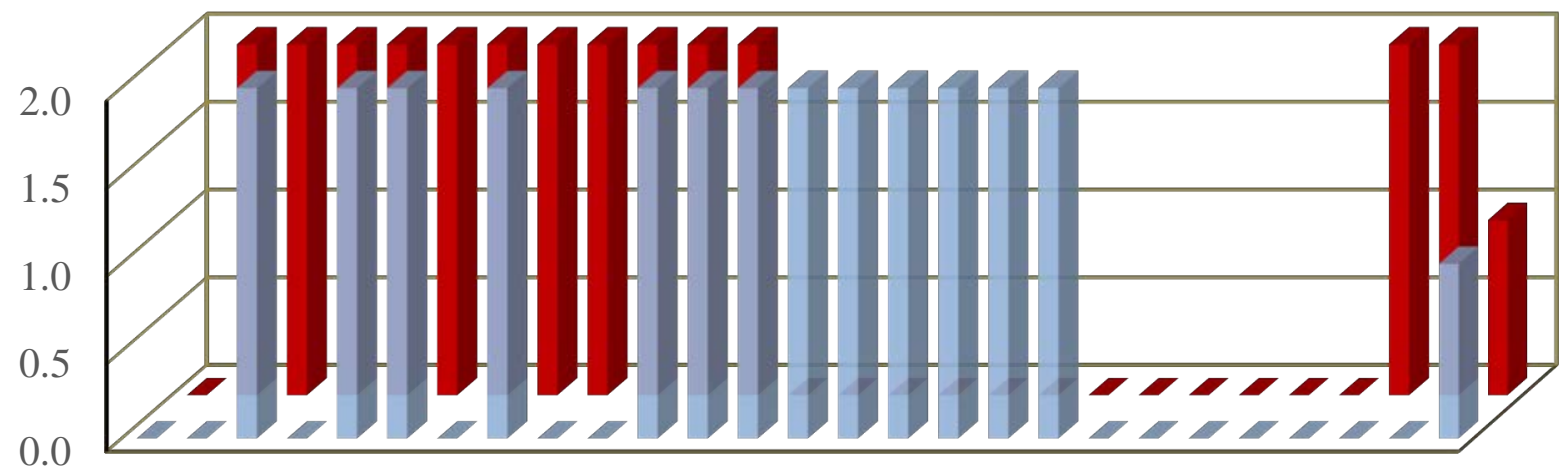

19871989199119931995199719992001200320052007200920112013

Buyout $\quad$ Venture Capital 
Figure 2. Buyout Capital Commitments for Alternative Strategies

This figure provides the capital commitment schedule for buyout funds for the fixed, pro-cyclical, and counter-cyclical strategies discussed in the text based on annual fundraising relative to its rolling 3year average. Annual commitments are capped at 200\%.

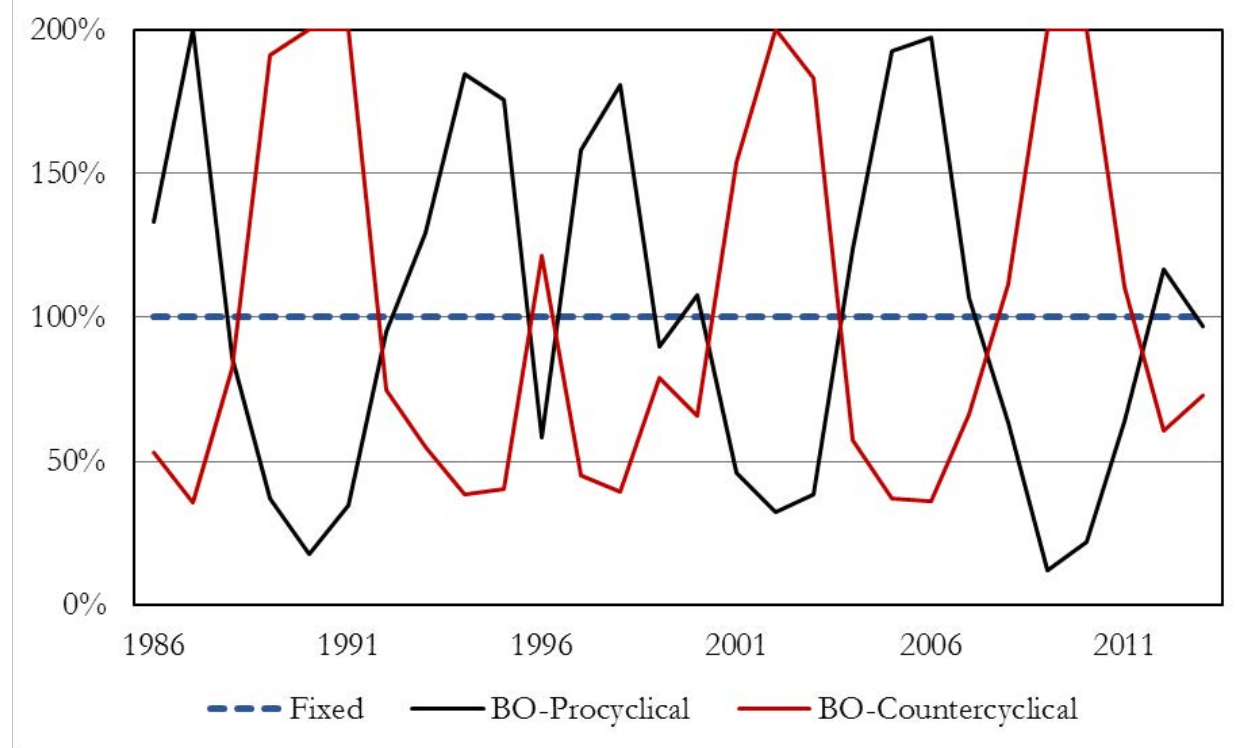

Figure 3. Venture Capital Commitments for Alternative Strategies

This figure provides the capital commitment schedule for venture capital funds for the fixed, procyclical, and counter-cyclical strategies discussed in the text based on annual fundraising relative to its rolling 3-year average. Annual commitments are capped at 200\%.

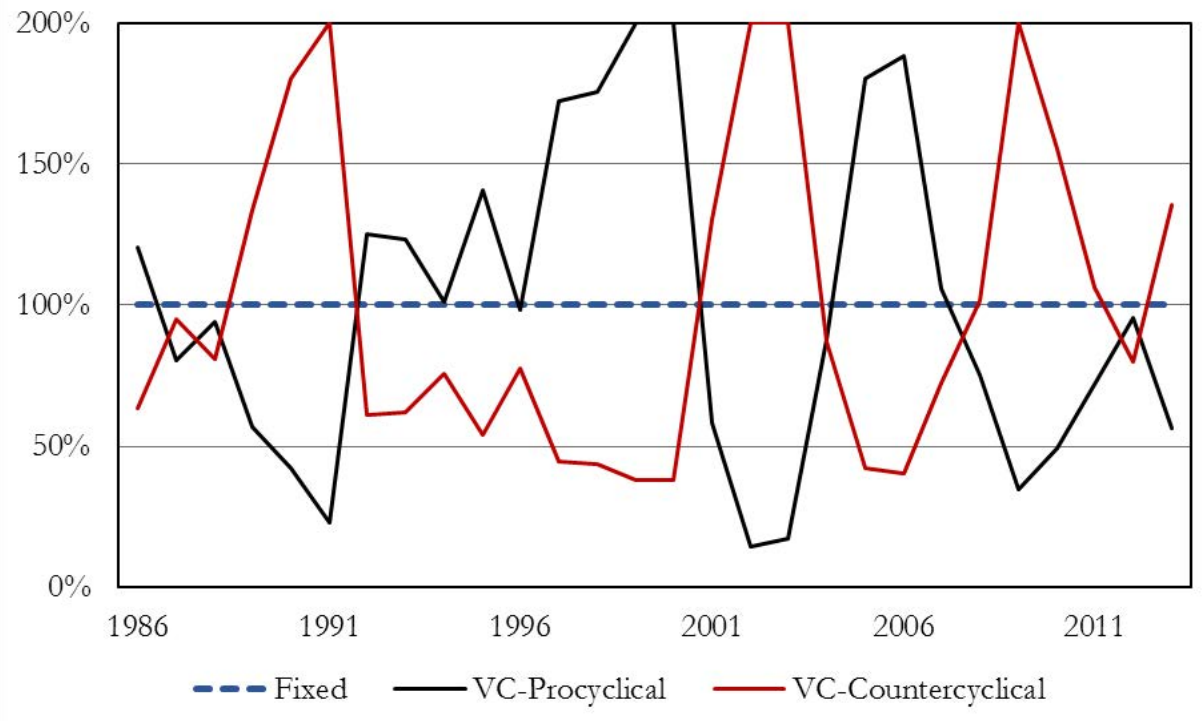




\section{Figure 4. Diversification and Portfolio Effects on Performance}

This figure plots the distribution of portfolio PMEs for a fixed annual allocation strategy based on simulated portfolios with different numbers of randomly selected funds $(\mathrm{N}=1,3,5,7,15,30)$ in each vintage. Panel A shows results for buyout funds, and Panel B shows results for venture capital funds.

Panel A. Buyout Funds

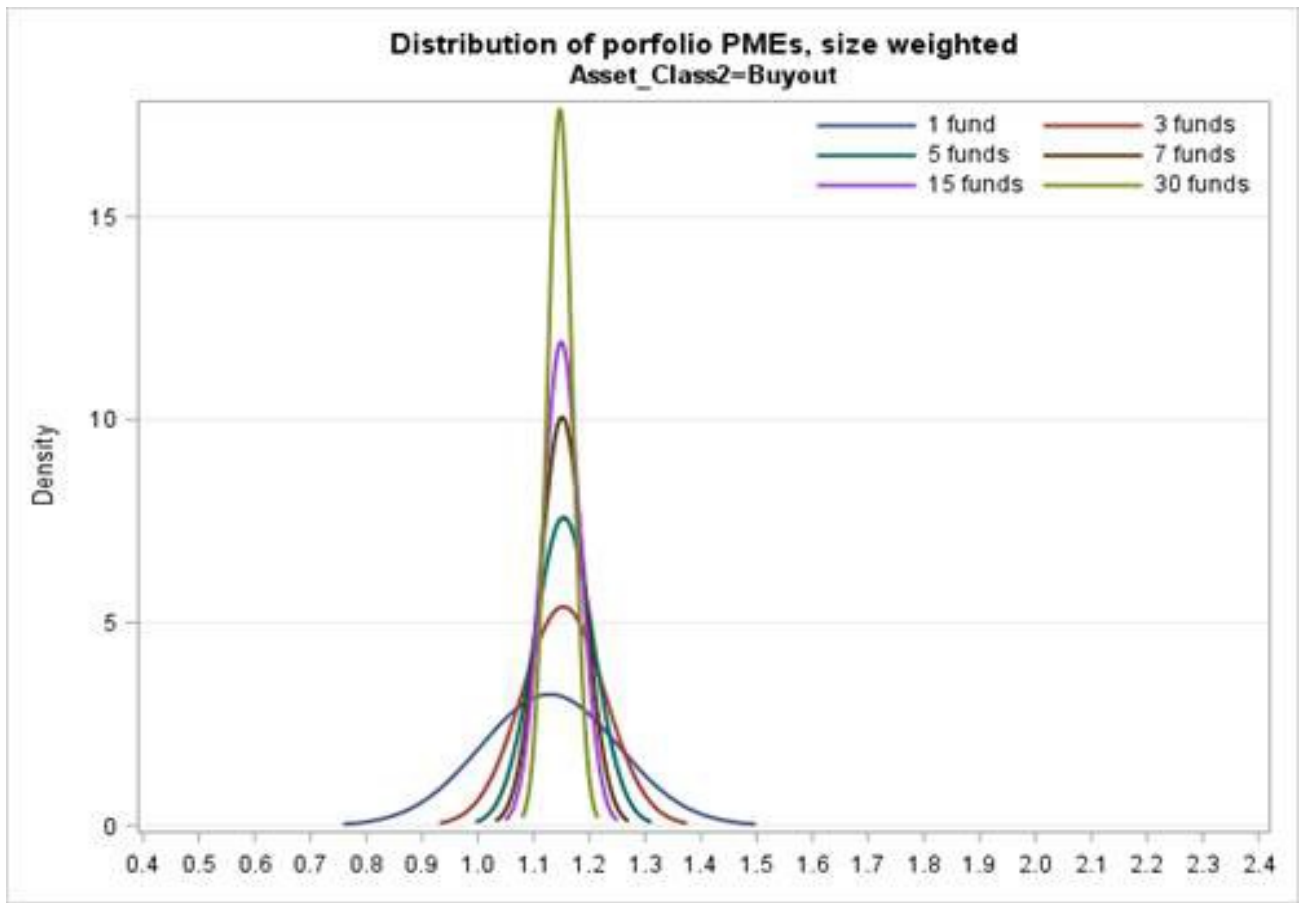

Panel B: Venture Capital Funds

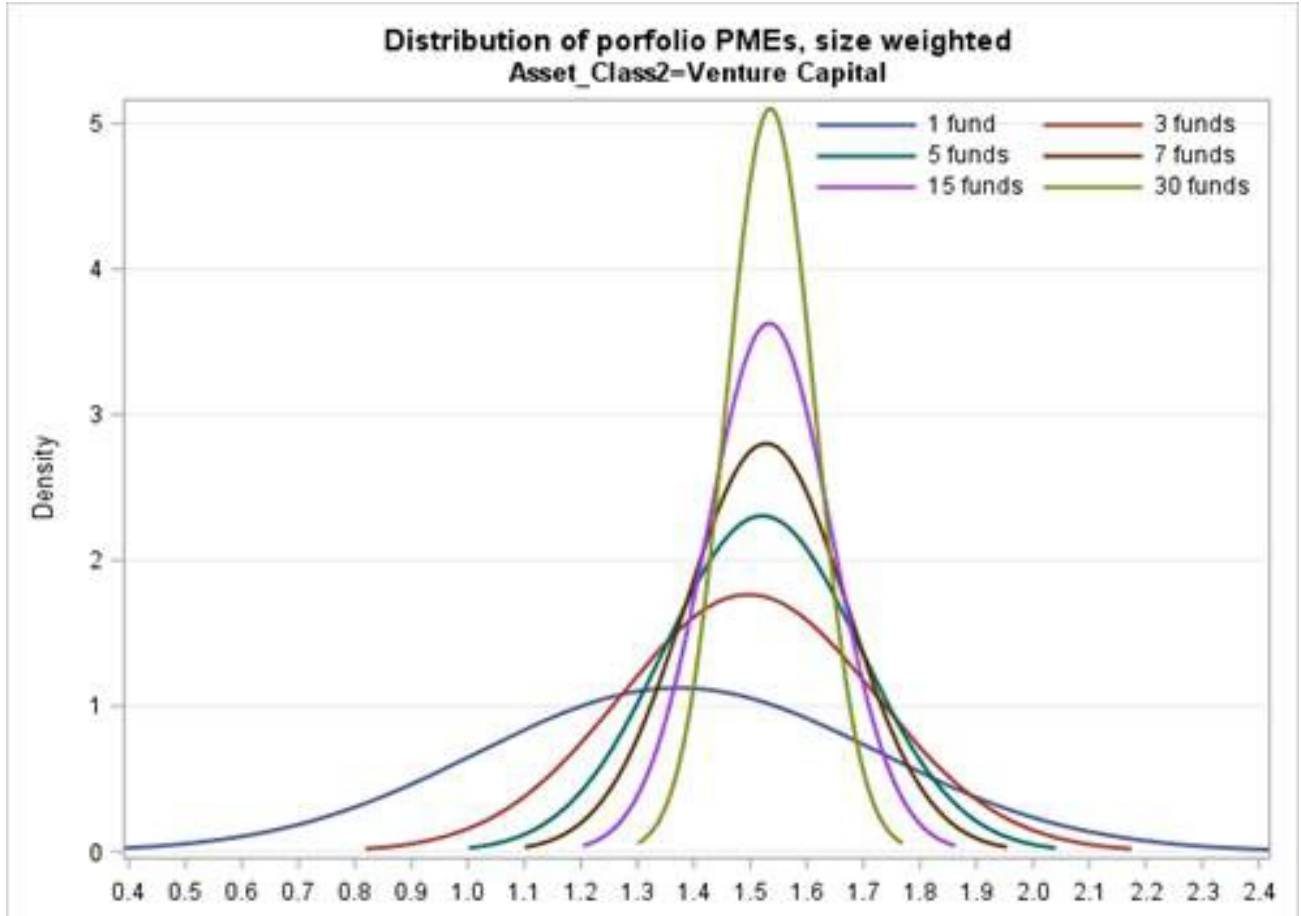


Figure 5. Buyout Cash Calls and Distributions

This figure provides the capital calls (Panel A) and distributions (Panel B) for the fixed annual, pro-cyclical , and counter-cyclical strategies based on recent fundraising scaled by a three year rolling average as discussed in the text. We assume a $\$ 100$ commitment per year in the fixed allocation and average of $\$ 100$ per year in the pro-cyclical and counter-cyclical strategies.

\section{Panel A: Capital Calls (Drawdowns)}

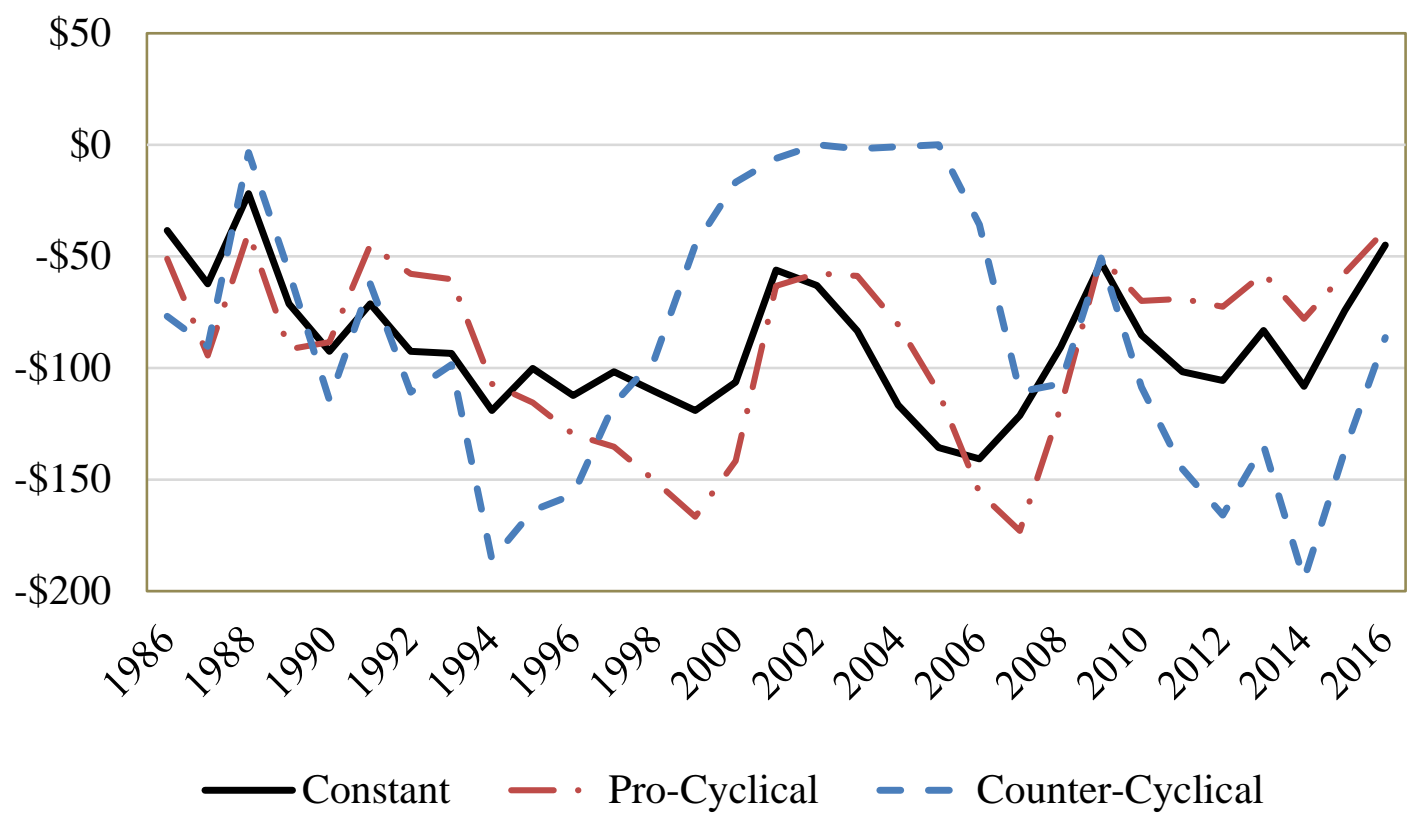

Panel B: Capital Distributions

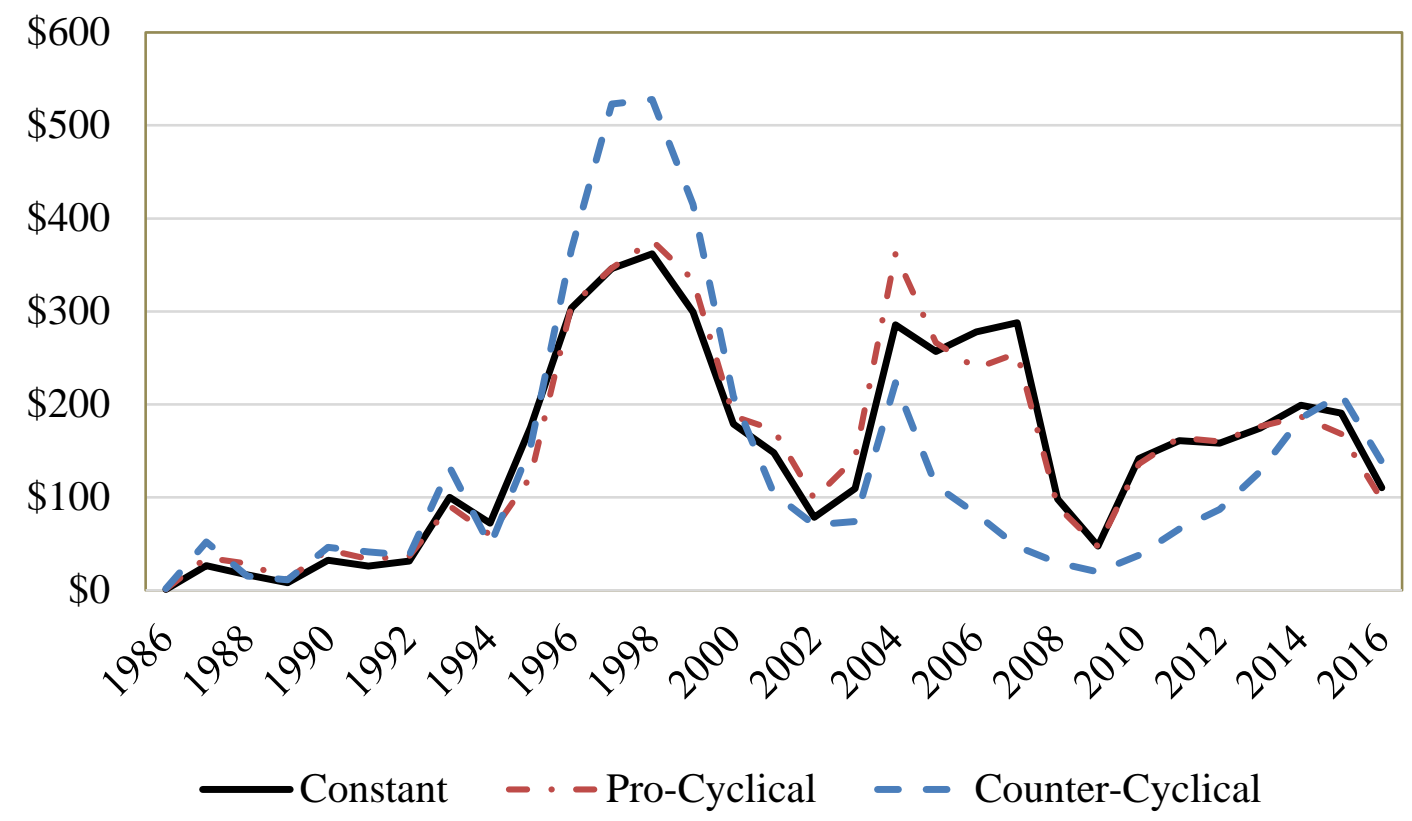


Figure 6. Venture Capital Cash Calls and Distributions

This figure provides the capital calls (Panel A) and distributions (Panel B) for the fixed annual, procyclical, and counter-cyclical strategies based on recent fundraising scaled by a three year rolling average as discussed in the text. We assume a $\$ 100$ commitment per year in the fixed allocation and average of $\$ 100$ per year in the pro-cyclical and counter-cyclical strategies.

Panel A: Capital Calls (Drawdowns)

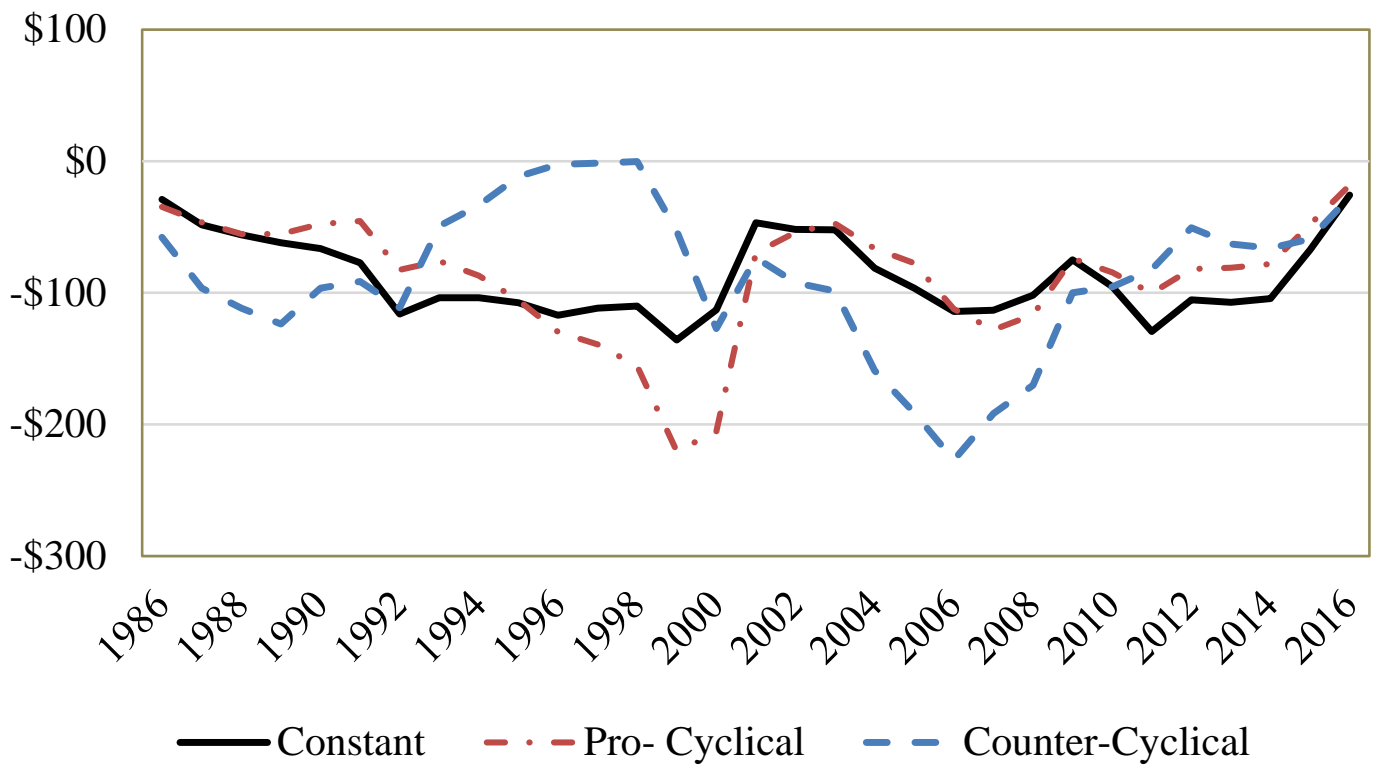

Panel B: Capital Distributions

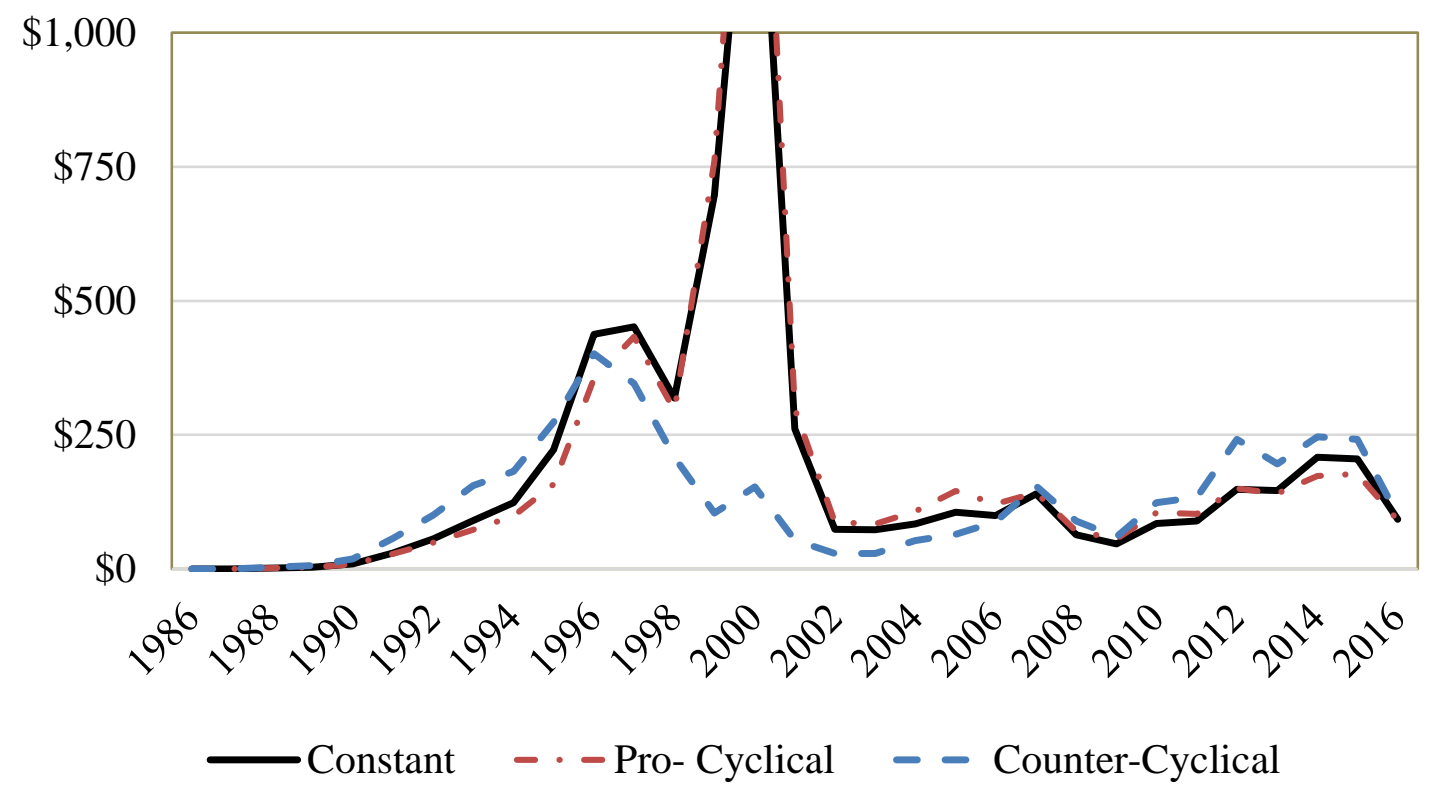


Table I. Fundraising and Aggregate Performance in Private Equity

This table reports regressions of private equity performance on aggregate fundraising in a vintage year. Panel A focuses on buyout funds, while Panel B focuses on venture capital funds. Dependent variables are measures of performance: the internal rate of return (IRR), multiple of invested capital (M0IC,) and the public market equivalent (PME) all estimated based on pooling across all funds of that vintage year. The independent variable is the current year's total fundraising from Burgiss scaled by the CRSP value-weighted market index as described in the text. The vintage years are 1987 through 2013, and the data go through Q3 2016. ***, ** and * denotes significance at the 1\%, 5\% and $10 \%$ levels respectively.

\begin{tabular}{lccc}
\multicolumn{4}{c}{ Panel A: Buyout Performance } \\
& IRR & MOIC & PME \\
\hline \hline Fund Raising Scaled by & $-13.76^{* * *}$ & $-0.81^{* * *}$ & $-0.23^{*}$ \\
Stock Market Value & {$[-4.18]$} & {$[-4.40]$} & {$[-1.83]$} \\
& & & \\
Constant & $21.73^{* * *}$ & $2.14^{* * *}$ & $1.28^{* * *}$ \\
& {$[12.47]$} & {$[21.90]$} & {$[18.91]$} \\
Observations & & & \\
R-Squared & 27 & 27 & 27 \\
\hline \hline
\end{tabular}

Panel B: Venture Capital Performance

\begin{tabular}{lccc} 
& IRR & MOIC & PME \\
\hline \hline Fund Raising Scaled by & $-216.73^{* * *}$ & $-14.36^{* * *}$ & $-5.87^{* *}$ \\
Stock Market Value & {$[-2.82]$} & {$[-3.36]$} & {$[-2.60]$} \\
& & & \\
Constant & $48.92^{* * *}$ & $3.98^{* * *}$ & $2.04^{* * *}$ \\
& {$[5.38]$} & {$[7.87]$} & {$[7.63]$} \\
& & & \\
Observations & 27 & 27 & 27 \\
R-Squared & 0.24 & 0.31 & 0.21 \\
\hline \hline
\end{tabular}




\section{Table II. The Performance of Alternative Capital Allocation Strategies}

This table reports performance statistics for alternative private equity commitment strategies. MOIC is the ratio of total value to paid-in capital. Total value is the sum of the cash returned to investors and the remaining NAV as estimated by the private equity (PE) fund manager. PMEs compare PE returns to equivalent-timed investments in the S\&P 500. Direct- $\alpha$ (direct alpha) is the rate which added to the public market rate leads to a PME of 1.0. Panel A focuses on buyout funds, and Panel B on VC funds, as classified by Burgiss. The strategies cover vintage years 1987 through 2013, and the data go through Q3 2016.

Panel A: Buyout Funds

\begin{tabular}{lcccc} 
Commitment Strategy & PME & Direct- $\alpha$ & IRR & MOIC \\
\hline \hline Fixed Annual Commitment & 1.15 & $2.8 \%$ & $16.5 \%$ & 1.80 \\
& & & & \\
Strategies relying on foresight (using actual PMEs) & & & & \\
$\quad$ Foresight & 1.35 & $7.4 \%$ & $21.4 \%$ & 1.94 \\
Anti-foresight & 0.97 & $-0.6 \%$ & $13.4 \%$ & 1.65
\end{tabular}

Allocations based on fundraising scaled by 3-year rolling average

$\begin{array}{lllll}\text { Pro-cyclical } & 1.10 & 1.8 \% & 14.3 \% & 1.74 \\ \text { Counter-cyclical } & 1.20 & 4.0 \% & 18.9 \% & 1.89\end{array}$

Allocations based on fundraising scaled by stock market

$\begin{array}{lllll}\text { Pro-cyclical } & 1.09 & 1.8 \% & 14.9 \% & 1.75 \\ \text { Counter-cyclical } & 1.17 & 3.5 \% & 18.1 \% & 1.86\end{array}$

Allocations based on dry powder scaled by 3-year rolling average

$\begin{array}{lllll}\text { Pro-cyclical } & 1.10 & 1.8 \% & 14.7 \% & 1.79 \\ \text { Counter-cyclical } & 1.21 & 4.6 \% & 19.7 \% & 1.81\end{array}$

Allocations based on dry powder scaled by NAV of active funds

\begin{tabular}{lllll} 
Pro-cyclical & 1.12 & $2.1 \%$ & $14.6 \%$ & 1.78 \\
Counter-cyclical & 1.18 & $3.9 \%$ & $19.1 \%$ & 1.81 \\
\hline
\end{tabular}


Table II. The Performance of Alternative Capital Allocation Strategies (continued) Panel B: Venture Capital Funds

\begin{tabular}{lcccc} 
Commitment Strategy & PME & Direct- $\alpha$ & IRR & MOIC \\
\hline \hline Fixed Annual Commitment & 1.54 & $10.2 \%$ & $29.1 \%$ & 2.52 \\
& & & & \\
Strategies relying on foresight (using actual PMEs) & & & & \\
$\quad$ Foresight & 1.84 & $13.8 \%$ & $33.8 \%$ & 3.49 \\
$\quad$ Anti-foresight & 0.99 & $-0.3 \%$ & $9.3 \%$ & 1.56
\end{tabular}

Allocations based on fundraising scaled by 3-year rolling average

$\begin{array}{lcccc}\text { Pro-cyclical } & 1.62 & 11.9 \% & 31.2 \% & 2.54 \\ \text { Counter-cyclical } & 1.43 & 8.7 \% & 27.2 \% & 2.38\end{array}$

Allocations based on fundraising scaled by stock market

$\begin{array}{lllll}\text { Pro-cyclical } & 1.54 & 10.4 \% & 29.0 \% & 2.39 \\ \text { Counter-cyclical } & 1.51 & 10.0 \% & 29.1 \% & 2.59\end{array}$

Allocations based on dry powder scaled by 3-year rolling average

$\begin{array}{lllll}\text { Pro-cyclical } & 1.52 & 10.1 \% & 28.6 \% & 2.42 \\ \text { Counter-cyclical } & 1.55 & 10.4 \% & 29.5 \% & 2.62\end{array}$

Allocations based on dry powder scaled by NAV of active funds

\begin{tabular}{lcccc} 
Pro-cyclical & 1.42 & $9.6 \%$ & $28.3 \%$ & 2.12 \\
Counter-cyclical & 1.61 & $10.5 \%$ & $29.4 \%$ & 2.94 \\
\hline \hline
\end{tabular}


Table III. The Performance of Timing Strategies with Different Restrictions on Annual Variations in Capital Allocations

This table reports performance statistics for two alternative private equity commitment strategies. The first sets a maximum annual allocation and constrains allocation weights over the study period. The second relaxes those constraints, allowing for more variation in allocations across vintage years. MOIC is the ratio of total value to paid-in capital. Total value is the sum of the cash returned to investors and the remaining NAV as estimated by the private equity (PE) fund manager. PMEs compare PE returns to equivalent-timed investments in the S\&P 500. Direct- $\alpha$ (direct alpha) is the rate which added to the public market return leads to a PME of 1.0. Panel A focuses on buyout funds, and Panel B on VC funds, as classified by Burgiss. The strategies cover vintage years 1987 through 2013, and the data go through Q3 2016.

Panel A: Buyout Funds

\begin{tabular}{lllll} 
Commitment Strategy & PME & Direct- $\alpha$ & IRR & MOIC \\
\hline \hline
\end{tabular}

Fundraising scaled by stock market, with maximum allocation and allocation weights constrained

$\begin{array}{lllll}\text { Pro-cyclical } & 1.09 & 1.8 \% & 14.9 \% & 1.75 \\ \text { Counter-cyclical } & 1.17 & 3.5 \% & 18.1 \% & 1.86\end{array}$

Fundraising scaled by stock market, no constraints on maximum value or weights

\begin{tabular}{lllll} 
Pro-cyclical & 1.07 & $1.2 \%$ & $14.3 \%$ & 1.77 \\
Counter-cyclical & 1.18 & $3.5 \%$ & $18.2 \%$ & 1.86 \\
\hline \hline
\end{tabular}

Panel B: Venture Capital Funds

Commitment Strategy

PME Direct- $\alpha \quad$ IRR $\quad$ MOIC

Fundraising scaled by stock market, with maximum allocation and allocation weights constrained

$\begin{array}{lllll}\text { Pro-cyclical } & 1.54 & 10.4 \% & 29.0 \% & 2.39 \\ \text { Counter-cyclical } & 1.51 & 10.0 \% & 29.1 \% & 2.59\end{array}$

Fundraising scaled by stock market, no constraints on maximum value or weights

\begin{tabular}{lllll} 
Pro-cyclical & 1.50 & $10.0 \%$ & $28.4 \%$ & 2.26 \\
Counter-cyclical & 1.51 & $10.0 \%$ & $29.1 \%$ & 2.61 \\
\hline \hline
\end{tabular}




\section{Table IV. The Performance of Binary-Cyclical Strategies for Private Equity Allocations}

This table reports performance results for binary-cyclical strategies that are based on whether fundraising is high in a given year. In an "avoid allocations in high years" strategy, a vintage year has a zero allocation if fundraising is high in that year, \$100 otherwise. Entries are the public market equivalent (PME) and number of vintage years with non-zero allocations in that strategy. "High" fundraising is defined by setting threshold values as multiples of past levels. For each year, we separately scale venture and buyout fundraising by total stock market capitalization. We then compute a dynamic, backward-looking, average from year 1980 to the previous year. A year is classified as a "high” fundraising year if the current year's scaled fundraising level is above a threshold of X times the dynamic average. The data include all funds with 1987-2013 vintage years, with data going through the third quarter of 2016.

Threshold for vintage to classify as "high" fundraising year

\begin{tabular}{|c|c|c|c|c|c|c|c|}
\hline \multicolumn{2}{|c|}{$X=1.0$} & \multicolumn{2}{|c|}{$X=1.5$} & \multicolumn{2}{|c|}{$X=2.0$} & \multicolumn{2}{|c|}{$X=2.5$} \\
\hline PME & $\begin{array}{l}\text { No. of } \\
\text { Alloc. }\end{array}$ & PME & $\begin{array}{l}\text { No. of } \\
\text { Alloc. }\end{array}$ & PME & $\begin{array}{l}\text { No. of } \\
\text { Alloc. }\end{array}$ & PME & $\begin{array}{l}\text { No. of } \\
\text { Alloc. }\end{array}$ \\
\hline
\end{tabular}

Buyout Funds

$\begin{array}{lllllllll}\text { Avoid Allocations to High Years } & 1.17 & 4 & 1.21 & 14 & 1.22 & 15 & 1.24 & 22 \\ \text { Allocate Only to High Years } & 1.14 & 23 & 1.09 & 13 & 1.06 & 12 & 0.92 & 5\end{array}$

Venture Capital Funds

\begin{tabular}{lllllllll} 
Avoid Allocations to High Years & 1.51 & 16 & 1.55 & 22 & 1.57 & 25 & 1.57 & 25 \\
Allocate Only to High Years & 1.58 & 11 & 1.40 & 5 & 0.77 & 2 & 0.77 & 2 \\
\hline
\end{tabular}




\section{Table V. The Performance of Strategies that Do Not Attempt to Time Allocations}

This table reports public market equivalents (PMEs) for different commitment strategies. Panel A focuses on variations of a fixed annual commitment strategy which makes the same dollar commitment to each vintage year and invests in all funds. Panel B reports results for strategies that have a fixed commitment per year but invest only in funds that fit certain characteristics in terms of the experience of the general partner (GP) or the fund size A fund is designated as "experienced GP" if the GP has raised at least two prior funds; "new GP" otherwise. Large funds are raising more than the median fund that vintage year; otherwise the fund is small. A strategy invests in only one type of fund, e.g. the experienced GP strategy places all of a vintage year's capital with experienced GPs weighted by fund size. The strategies cover vintage years 1987 through 2013 with data going through the third quarter of 2016.

Panel A: Variations of Fixed Annual Commitment Strategy

Commitment Strategy $\quad$ Buyout PME Venture PME

\begin{tabular}{lcc}
\hline \hline Fixed Annual Allocation (funds value-weighted) & 1.15 & 1.54 \\
Fixed Annual Allocation (funds equal-weighted) & 1.13 & 1.37 \\
Growing Annual Allocation at 5\% per year & 1.16 & 1.50 \\
Proportional to Annual Fundraising levels & 1.14 & 1.20 \\
\hline \hline
\end{tabular}

Panel B: Strategies Based on GP Experience or Fund Size

Commitment Strategy $\quad$ Buyout PME Venture PME

\begin{tabular}{lcc}
\hline \hline Experienced GPs (value-weighted) & 1.23 & 1.71 \\
“New” GPs (value-weighted) & 1.13 & 1.15 \\
& & \\
Larger than median-sized funds & 1.16 & 1.61 \\
Smaller than median-sized funds & 1.09 & 1.27 \\
\hline \hline
\end{tabular}


Table VI. Time-weighted Returns and Risks to Alternative Strategies

This table reports the public market equivalent (PME), as well as the quarterly mean net return, standard deviation (Volatility), and Sharpe ratio for a variety of commitment strategies in buyout funds (Panel A) and venture capital funds (Panel B). Returns are stated on an annual basis.

Panel A: Buyout Funds

\begin{tabular}{lcccc} 
Commitment Strategy & PME & Return & Volatility & Sharpe \\
\hline \hline Fixed Annual Allocation (funds value-weighted) & 1.15 & $14.5 \%$ & $12.2 \%$ & 1.19 \\
Fixed Annual Allocation (funds equal-weighted) & 1.13 & $12.4 \%$ & $9.6 \%$ & 1.29 \\
Growing Annual Allocation at 5\% per year & 1.16 & $14.6 \%$ & $12.2 \%$ & 1.19 \\
Proportional to Annual Fundraising levels & 1.14 & $13.3 \%$ & $12.8 \%$ & 1.04 \\
Experienced GPs (value-weighted) & 1.23 & $16.0 \%$ & $13.6 \%$ & 1.18 \\
"New” GPs (value-weighted) & 1.13 & $13.3 \%$ & $12.7 \%$ & 1.05 \\
Large Funds (variant of row 1) & 1.16 & $14.9 \%$ & $12.6 \%$ & 1.18 \\
Small Funds (variant of row 1) & 1.09 & $11.6 \%$ & $11.4 \%$ & 1.02 \\
& & & & \\
\hline \hline
\end{tabular}

Panel B: Venture Capital Funds

\begin{tabular}{lcccc} 
Commitment Strategy & PME & Return & Volatility & Sharpe \\
\hline \hline Fixed Annual Allocation (funds value-weighted) & 1.54 & $13.3 \%$ & $21.1 \%$ & 0.63 \\
Fixed Annual Allocation (funds equal-weighted) & 1.37 & $11.0 \%$ & $20.0 \%$ & 0.55 \\
& & & & \\
Growing Annual Allocation at 5\% per year & 1.5 & $13.6 \%$ & $21.5 \%$ & 0.63 \\
Proportional to Annual Fundraising levels & 1.2 & $13.5 \%$ & $21.7 \%$ & 0.62 \\
Experienced GPs (value-weighted) & 1.71 & $14.2 \%$ & $22.8 \%$ & 0.62 \\
"New” GPs (value-weighted) & 1.15 & $10.3 \%$ & $16.2 \%$ & 0.63 \\
Large Funds (variant of row 1) & 1.61 & $14.4 \%$ & $22.1 \%$ & 0.65 \\
Small Funds (variant of row 1) & 1.27 & $9.4 \%$ & $19.2 \%$ & 0.49 \\
& & & & \\
\hline \hline
\end{tabular}


Table VII. The Effects of Altering Timing Decisions on Investing Strategies

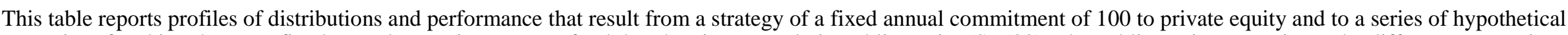

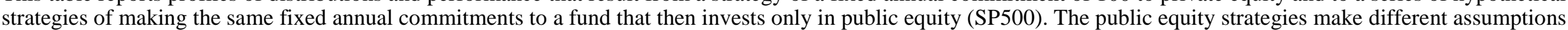

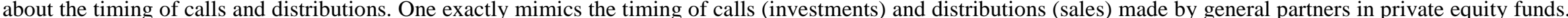

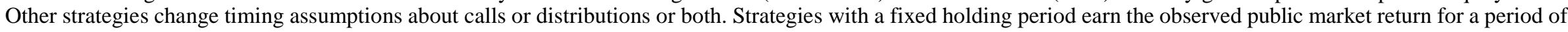

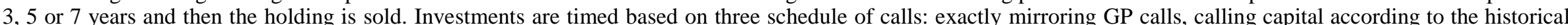

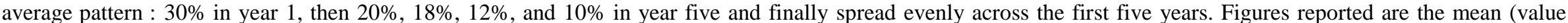

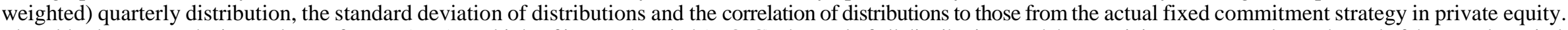

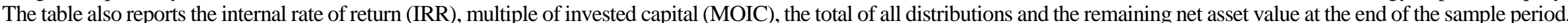

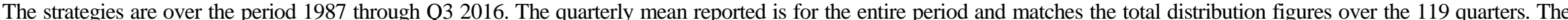

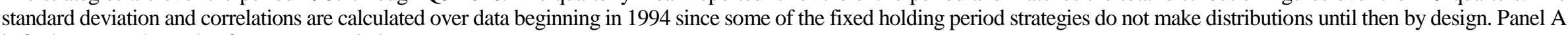
is for buyout and Panel B for venture capital.

\section{Panel A: Buyout Funds}

\begin{tabular}{|c|c|c|c|c|c|c|c|}
\hline Strategy/Benchmark & $\begin{array}{l}\text { Distribution } \\
\text { Mean }\end{array}$ & $\begin{array}{l}\text { Distribution } \\
\text { Std. }\end{array}$ & $\begin{array}{l}\text { Distribution } \\
\text { Correlation }\end{array}$ & IRR & MOIC & $\begin{array}{c}\text { Total } \\
\text { Distribution }\end{array}$ & $\begin{array}{c}\text { Final Valuation } \\
\text { (NAV) }\end{array}$ \\
\hline Fixed Annual Commitment & 35.4 & 20.9 & 1.00 & $16.5 \%$ & 1.80 & 4,218 & 584 \\
\hline \multicolumn{8}{|l|}{ Strategies Investing in Public Equity } \\
\hline Mimic GP Timing of calls and distributions & 29.4 & 19.2 & 0.92 & $14.0 \%$ & 1.50 & 3,502 & 495 \\
\hline \multicolumn{8}{|c|}{ Mimic GP capital calls with fixed holding periods } \\
\hline Three-year holding period & 27.8 & 18.6 & 0.35 & $14.3 \%$ & 1.34 & 3,307 & 287 \\
\hline Five-year holding period & 30.9 & 26.8 & 0.17 & $14.0 \%$ & 1.60 & 3,676 & 599 \\
\hline Seven-year holding period & 33.0 & 29.5 & 0.22 & $13.0 \%$ & 1.83 & 3,929 & 965 \\
\hline \multicolumn{8}{|c|}{ Calls based on historical average pattern for investment period, fixed holding period } \\
\hline Three-year holding period & 27.2 & 9.6 & 0.52 & $15.2 \%$ & 1.41 & 3,232 & 164 \\
\hline Five-year holding period & 30.4 & 15.8 & 0.37 & $14.7 \%$ & 1.69 & 3,620 & 472 \\
\hline Seven-year holding period & 32.8 & 20.1 & 0.24 & $14.1 \%$ & 1.97 & 3,902 & 853 \\
\hline \multicolumn{8}{|c|}{ Calls spread equally over five years, fixed holding period } \\
\hline Three-year holding period & 29.5 & 10.7 & 0.52 & $15.3 \%$ & 1.4 & 3,512 & 227 \\
\hline Five-year holding period & 33.0 & 17.7 & 0.39 & $14.8 \%$ & 1.68 & 3,922 & 570 \\
\hline Seven-year holding period & 35.3 & 22.8 & 0.24 & $14.1 \%$ & 1.94 & 4,196 & 994 \\
\hline
\end{tabular}


Table VII. The Effects of Altering Timing Decisions on Alternative Investing Strategies (continued)

Panel B: Venture Capital Funds

\begin{tabular}{|c|c|c|c|c|c|c|c|}
\hline Strategy/Benchmark & $\begin{array}{l}\text { Distribution } \\
\text { Mean }\end{array}$ & $\begin{array}{l}\text { Distribution } \\
\text { Std. }\end{array}$ & $\begin{array}{l}\text { Distribution } \\
\text { Correlation }\end{array}$ & IRR & MOIC & $\begin{array}{c}\text { Total } \\
\text { Distribution }\end{array}$ & $\begin{array}{l}\text { Final Valuation } \\
\text { (NAV) }\end{array}$ \\
\hline Fixed Annual Commitment & 47.1 & 89.5 & 1.00 & $29.1 \%$ & 2.52 & 5,601 & 1,018 \\
\hline \multicolumn{8}{|l|}{ Strategies Investing in Public Equity } \\
\hline Mimic GP Timing of calls and distributions & 27.4 & 25.7 & 0.82 & $14.9 \%$ & 1.57 & 3,257 & 866 \\
\hline \multicolumn{8}{|c|}{ Mimic GP capital calls with fixed holding periods } \\
\hline Three-year holding period & 27.7 & 14.4 & 0.46 & $14.0 \%$ & 1.36 & 3,300 & 258 \\
\hline Five-year holding period & 30.9 & 21.1 & 0.69 & $14.2 \%$ & 1.63 & 3,678 & 606 \\
\hline Seven-year holding period & 32.7 & 25.1 & 0.57 & $13.3 \%$ & 1.88 & 3,889 & 1,050 \\
\hline \multicolumn{8}{|c|}{ Calls based on historical average pattern for investment period, fixed holding period } \\
\hline Three-year holding period & 27.2 & 9.6 & 0.45 & $15.2 \%$ & 1.41 & 3,232 & 164 \\
\hline Five-year holding period & 30.4 & 15.8 & 0.64 & $14.7 \%$ & 1.69 & 3,620 & 472 \\
\hline Seven-year holding period & 32.8 & 20.1 & 0.63 & $14.1 \%$ & 1.97 & 3,902 & 853 \\
\hline \multicolumn{8}{|c|}{ Calls spread equally over five years, fixed holding period } \\
\hline Three-year holding period & 29.5 & 10.7 & 0.45 & $15.3 \%$ & 1.4 & 3,512 & 227 \\
\hline Five-year holding period & 33.0 & 17.7 & 0.64 & $14.8 \%$ & 1.68 & 3,922 & 570 \\
\hline Seven-year holding period & 35.3 & 22.8 & 0.61 & $14.1 \%$ & 1.94 & 4,196 & 994 \\
\hline
\end{tabular}

